\title{
Risk Transfer Mechanism for Agricultural Products Supply Chain Based on Weather Index Insurance
}

\author{
Hongyong Fu $\mathbb{D}^{\mathbb{D}}{ }^{1}$ Jiawen Li, ${ }^{1}$ Yujie Li, ${ }^{1}$ Shengzhong Huang $\mathbb{D}^{1},{ }^{1}$ and Xiangkai Sun ${ }^{2}$ \\ ${ }^{1}$ China Research Institute of Enterprise Governed by Law, Southwest University of Political Science and Law, 301 Baosheng Street, \\ Chongqing 401120, China \\ ${ }^{2}$ College of Mathematics and Statistics, Chongqing Technology and Business University, Chongqing 400067, China
}

Correspondence should be addressed to Shengzhong Huang; huangshengzhong@hotmail.com

Received 18 May 2018; Revised 6 July 2018; Accepted 30 July 2018; Published 14 August 2018

Academic Editor: Shoujun Huang

Copyright (c) 2018 Hongyong Fu et al. This is an open access article distributed under the Creative Commons Attribution License, which permits unrestricted use, distribution, and reproduction in any medium, provided the original work is properly cited.

The risk management for agricultural products supply chain is more complex than that for typical manufacturing supply chain. Agricultural production is vulnerable to severe weather such as heavy rain, cyclones, and cold wave, which challenges the matching of random output with random demand for agricultural products supply chains. The goal of this paper is to design an effective risk transfer mechanism for managing severe weather risks so as to ensure the stable operation of the agricultural products supply chain. We study the coordination of two-level agricultural products supply chain with a single company and a single farmer under the influence of severe weather. Taking rainstorm weather as an example, this paper designs a risk transfer mechanism based on weather index (rainfall) insurance: "rainfall index insurance + revenue sharing + risk transfer fee." It is found that this risk transfer mechanism can overcome distortion of the farmer's agricultural investment level under the influence of severe weather. When the contract parameters meet certain conditions, using the risk transfer mechanism can achieve the supply chain coordination and a win-win situation. More importantly, weather change does not affect the Pareto improvement of the company and the farmer under the risk transfer mechanism. In addition, we also find that the company can incentivize the farmer to purchase weather index insurance and use the insurance market to shift the severe weather risk encountered during the agricultural production to protect the company's and farmer's income and the stable operation of the supply chain.

\section{Introduction}

Agriculture is one of the most weather-sensitive industries. There is a clear coupling between agricultural production and weather changes, and it is particularly complex and special in developing economies [1]. On the one hand, the effects of weather changes on agricultural development have both advantages and disadvantages, and disadvantages are the main. For example, Ethiopia suffered severe drought in the 1980s, which caused great losses to farmer and affected the growth of income in the following decades [2]. In 2008, China suffered from low temperature, sleet, and freeze disaster and the affected arable land reaching $1431.8 \times 10^{4}$ hectares, resulting in a loss of crop yield of $197.1 \times 10^{4}$ hectares [3]. On the other hand, agriculture in developing economies tends to be dominated by small-scale farmer economies, and weather changes bring huge challenges to the agricultural production activities of "small farmers and big markets" [4]. Especially, the frequent severe weather such as heavy rain and cold wave will not only directly affect the production of upstream farmers in the agricultural products supply chain but also make downstream agriculture-related companies face a challenge: How to match a random output with random demand?

In response to the weather risk encountered in agricultural production activities, some experts studied the design of the corresponding contract mechanism from the dimension of supply chain operational hedging in order to minimize the losses caused by weather risk [5-7]. However, these studies mainly focus on the design of coordination mechanisms among supply chain members, lacking effective risk externalization mechanisms. Some scholars use financial 
derivative market to transfer the weather risk and study the (weather) option contract design of the agricultural products supply chain. Although the option-based risk externalization mechanism can transfer uncontrollable risks encountered within the supply chain, weather option is mainly used to counter adverse weather risks such as warm winter and cold spring [8]. For heavy rain and other severe weather encountered during agricultural production, the option mechanism is difficult to hedge relative risk effectively. In addition, the development of the financial derivative market in developing economies lags behind. These make it difficult to transfer disastrous weather risk during agricultural production through weather option in agricultural practice.

Agricultural insurance provides a solution to managing the severe weather risk encountered in agricultural production in developing economies. However, traditional agricultural insurance faces two major problems in the practice of agricultural production. One is insurance fraud caused by moral hazard and information asymmetry; the other is that policyholders cannot get compensation for losses due to basis risk. In contrast, weather index insurance takes the weather index (such as rainfall and temperature) as an object of compensation [9]. It can effectively overcome the information asymmetry in traditional agricultural insurance, avoiding moral hazard and adverse selection.

Based on the application of weather index insurance in agricultural practice and the characteristics of agricultural production in developing economies, this paper studies the two-level agricultural products supply chain system consisting of a single company and a single farmer. This paper, taking rainstorm disastrous weather as an example, aims to design a risk transfer mechanism based on weather index (rainfall) to reduce the impact of severe weather on agricultural products supply chain to improve the company's and the farmer's income. In particular, we wish to answer the following questions.

(1) How does disastrous weather affect farmers' optimal agricultural investment level and the profits of the company, farmer, and supply chain?

(2) Is the traditional coordination mechanism still effective in coordinating agricultural products supply chain under the influence of severe weather? If it is invalid, which factor will affect the design of the parameters of the coordination mechanism? How does it affect?

(3) How to design an effective, fair, and flexible risk transfer mechanism to achieve the perfect coordination of agricultural products supply chain under the influence of severe weather?

The rest of this study is organized as follows. In Section 2, we summarize the related theoretical and behavioral literature. We provide the details of our model in Section 3. Section 4 provides an analysis of the basic model: centralized decision model in Section 4.1, decentralized decision model in Section 4.2, and comparison between centralized and decentralized chains in Section 4.3. We design the risk transfer mechanism based on weather index insurance in Section 5. Then, in Section 6, we give some numerical examples. Finally, we conclude this paper with discussion and managerial insights in Section 7.

\section{Literature Review}

In this paper, our work is closely related to the literature on quantitative risk management models for agricultural products supply chain and supply chain coordination with contracts. These studies are briefly reviewed below.

The agricultural products supply chain risk management is even more important due to challenges associated with seasonality, supply spikes, and long supply lead times when compared with the risk management for typical manufacturing supply chains [10]. Within this field, mathematical models for agricultural problems have received widely attention $[11,12]$. To the best of our knowledge, van Berlo is the first quantitative study that considered risks in supply chains in this field, although without directly referring to the term "supply chain" [13]. Kazaz develops a single long-period production planning model for an olive oil supply chain by determining optimal leased farms and the production policy [14]. Lodree and Uzochukwu consider an inventory model for perishables in a fresh vegetable supply chain that maximizes expected profit by determining the optimal planting batch in each harvest period [15]. Ahumada and Villalobos investigate a multiperiod operational production and distribution planning model in a crop supply chain with the price and yield uncertainty [16]. Paksoy et al. develop a fuzzy network design in a consumable vegetable oil supply chain that minimizes the total transportation cost with probabilistic market demand [17]. Cai and Zhou study a production and transportation model that minimizes the expected total cost of production in a perishable fresh-crop supply chain [18]. Boyabatl considers a single-period and multiproduct food production planning model that maximizes the expected profit of processing firm by determining the procurement policy in fixed proportional production [19]. Wiedenmann and Geldermann develop a supply planning model for linseed oil processor in a polymer production supply chain that maximizes the expected profit with the raw material quantity and quality uncertainty [20]. As discussed above, quantitative agricultural risk models have been discussed in various contexts of farm management, production management, scheduling, and pest/disease management for supply chains in different crops.

Key considerations of agricultural problems (i.e., yield, harvest time, demand, etc.) are influenced by different sources of uncertainty such as weather conditions, animal or crop diseases, and price variability. Our research is most closely related to weather-related uncertainty and related risk management methodologies. Chen and Yano consider a supply chain for a seasonal product (including agricultural product) whose demand is its weather sensitivity and the design of the weather-linked rebate contract with many different forms that Pareto are improving [8]. Gao et al. study that retailers of seasonal products (including agricultural products) adopt weather-conditional rebate programs to induce early sales 
and show that the weather-conditional rebate program can increase sales by discriminating price in a customer's postpurchase states [21]. Yi and $\mathrm{Li}$ investigate the risk management of agricultural products supply chain in China by designing weather compensatory contract under weatherrelated demand [22]. Bertrand et al. study the precise relationship between weather and sales for strategic and financial decision making and show the way to use weather derivatives to offset the potential loss [23]. Hekimoğlu et al. examine a risk-averse distributor's decision on the choice between bottled wine and wine futures with the weather and market uncertainty [24]. Buchheim and Kolaska test whether customers are affected when they buy advance tickets for an outdoor movie theater and find that customers' decisions are heavily influenced by the weather at the time of purchase [25]. Unlike these studies, we focus on the design of a decentralized agricultural products supply chain coordination contract by the risk transfer mechanism based on weather index insurance.

Setting the supply chain coordination mechanisms between individual parties has been widely studied [26]. Revenue-sharing contract is one of the most popular mechanisms and has received considerable attention in supply chain literature [27]. At present, some studies focus on the supply chain coordination among the actors. For example, Burer et al. study a contract model between a large seed supplier and multiple retailers in a seed supply chain that maximizes the expected total channel of profit by determining contract parameters that result in supply chain coordination [28]. Cai et al. develop a model to characterize each party's optimal decisions on both decentralized and centralized fresh product supply chain systems and further develop an incentive scheme to facilitate coordination between the two parties [29]. Chen and Xiao study the coordination mechanism and the effects of the reordering policy on the coordination mechanism [30]. Asian and Nie investigate a buyer-backup supplier coordination model that maximizes the expected profit by determining the buyer firm's reserve quantity and the backup supplier's installed capacity in a single-period (short-life) food supply chain [31]. Ren et al. develop a supermarket-farmer coordination model in an agricultural commodity supply chain that distributes the profit and improves its effectiveness [32]. Zhao et al. study the green supply chains under capital constraints and design a new two-way revenue-sharing contract to coordinate the green supply chain and obtain a win-win outcome [33]. However, these studies do not take the weather-related yield environment into consideration. Furthermore, these coordination mechanisms do not consider weather index.

Our work is most closely related to three of these studies, including Ye et al. [4], Zhao and Wu [5], and Chen and Yano [8]. Ye et al. design an RPG (revenue sharing + production cost sharing + guaranteed money) mechanism to facilitate the coordination of contract farming supply chain under stochastic yield and demand [4]. Our work differs from Ye et al. [4] in the following aspects. First, we focus on investigating the effects of disastrous weather on optimal decisions and coordination mechanism, whereas they focus on the uncertainty of demand and yield on optimal decisions and coordination mechanism. Second, we design a risk transfer mechanism based on weather index insurance so as to shift weather risk to insurance market. Zhao and $\mathrm{Wu}$ study the coordination of agri-food chain with revenue-sharing contract under stochastic output and stochastic demand [5]. Our model differs from that by Zhao and $\mathrm{Wu}$ [5] in the following manner. In our model, the farmer does not have the right to make the wholesale price decision due to his weak bargaining power in developing economies. Furthermore, our model focuses on the problem of weather risk transfer in agricultural products supply chain. Chen and Yano study the performance improvement of seasonal supply chain under weather-sensitive demand [8]. Our model is distinguished from Chen and Yano [8] in several ways. First, we investigate agricultural products supply chain coordination with weather-related yield and demand uncertainty. Second, we design a coordination contract based on weather index insurance, whereas they design a weather option contract to coordinate seasonal supply chain. Hence, we position our study as an extension to the supply chain coordination and agricultural products supply chain risk management.

\section{Problem Description}

This paper examines a two-level agricultural products supply chain system consisting of a single company and a single farmer. This system produces and sells a single agricultural product in a region of developing economies. Before the growing season, the company and the farmer sign purchasing contracts in which the company promises to purchase all the agricultural products at the protection price of $\max \left\{w_{\mathrm{C}}, w\right\}$ when the selling season comes, where $w_{\mathrm{C}}$ is the guaranteed price decided by the company, $w$ is a random purchase price in the random demand market, and the probability density function and probability distribution function of $w$ in the interval $[L, U]$ are $h(\cdot)$ and $H(\cdot)$, respectively. Subsequently, the company processes and packages the purchased agricultural products and sells them at retail price of $p$ in the stochastic consumer market. The decision sequence in the agricultural products supply chain system is as follows: The farmer decides $I$, the level of agricultural investment in the production process of agricultural products. It is used to measure the farmer's investment in seeds, pesticides, chemical fertilizers, and other agricultural assets during the production of agricultural products and the level of efforts to prevent various risks (such as weather risk) with $I \in[0,1]$. After the growing season, the company bases on $w_{\mathrm{F}}$, the reservation price of farmer, to determine $w_{\mathrm{C}}$, the guaranteed price of agricultural products, and acquires all products produced by the farmer in accordance with the contractual agreement. The company faces $D$, the uncertain consumer demand, whose probability density function and distribution function are $f(\cdot)$ and $F(\cdot)$, respectively. For the sake of analysis, it is assumed that the company and the farmer are rational decision-making bodies and pursue personal interest maximization; the unit out-of- 
stock loss the company faces is $v$, and because the residual value of agricultural products is low and the treatment cost is relatively small, the residual value of unsold agricultural products is without consideration.

Both the company and the farmer can observe various weather conditions encountered in the production of agricultural products, such as cyclones, rainstorms, cold waves, and droughts. This paper, adopting the method of studying the weather risk by single weather index (such as temperature and rainfall) in the literature [34, 35], uses the rainfall as an example to study the risk transfer mechanism design of agricultural supply chain. We use $r$ to characterize the average amount of rainfall during the production of agricultural products, where the rainfall index $r \in[0, \underline{r}) \subset[0, \underline{r}) \subset\left[0, r_{1}\right) \subset\left[0, r_{2}\right) \subset[0, \bar{r}]$, $\underline{r}$ and $\underline{r}$ denote the lower and upper bounds of the rainfall suitable for the growth of the crop, respectively; $r_{1}$ and $r_{2}$ represent the lower and upper bounds of disastrous rainfall experienced during the growth of the crop, and $\bar{r}$ indicates the upper bound of rainfall that may occur in nature, and $\underline{\underline{r}}, \underline{r}, r_{1}, r_{2}$, and $\bar{r}$ are uncontrollable exogenous variables. Specifically, when $r \in\left[\underline{\underline{r}}, r_{1}\right)$, it means that nondisastrous weather (including $r \in[\underline{r}, \underline{r}$ ), the weather suitable for the growth of crops, and $r \in\left[\underline{r}, r_{1}\right)$, the adverse weather unfavorable to the growth of crops, such as warm winter and last spring coldness) occurs during agricultural production. When $r \in\left[r_{1}, r_{2}\right)$, it means disastrous weather occurs in the production process of agricultural products, such as cyclones and torrential rains. When $r \in\left[r_{2}, \bar{r}\right]$, it means that extreme weather that causes a total loss of agricultural products occurs, such as extremely heavy rainfall, where $r_{2}$ is the trigger point of extremely heavy rainfall. Without loss of generality, this paper takes the heavy rain disaster weather $\left(r \in\left[r_{1}, r_{2}\right)\right)$ as an example to study the risk transfer mechanism of agricultural products supply chain under the influence of heavy rain disaster weather, in order to hedge the severe weather risk encountered in the supply chain system. A similar analysis can be made on the design of risk transfer mechanisms for agricultural products supply chain under the influence of other severe weather (such as cyclones, droughts, and cold waves).

In order to quantitatively analyze the impact of heavy rain on the decisions of the company and the farmer during the production of agricultural products, we make the following assumptions: The cost of the farmer investing in the production of agricultural products is $C(I)$, which increases with the increase of agricultural investment level $I$ and shows a law of increasing marginal cost. The output of agricultural products $Q=Q(I, r)$ is determined by both rainfall $r$ and agricultural investment level $I$ and is the strictly increasing concave function of agricultural investment level $I$, which means that the output of agricultural products increases with the increase of agricultural investment level $I$ and shows a law of diminishing marginal returns. When $r_{1} \leq r<r_{2}$, it means that severe weather reducing output of agricultural products occurs, and that output $Q$ and rainfall $r$ are negatively correlated. When $r_{2} \leq r \leq \bar{r}$, it indicates that excessive rainfall occurs during the production of agricultural products; the extreme weather causes a total loss, that is, output $Q(I, r)=0$. In addition, as uncontrollable weather changes affect the farmer's decision making on the agricultural investment level, we assume that $Q(I, r)$ is a submodel function [36, 37] with respect to $(I, r)$, namely, $\partial^{2} Q(I, r) / \partial I \partial r<0$. It should be noted that changes in the level of agricultural investment do not impact the weather conditions, which means that there is only a one-way ( $r$ affects $I$ ) impact relationship between the level of agricultural investment and the rainfall index.

The basic model and risk transfer mechanism will be studied, respectively, in Sections 4 and 5. For ease of reference in Sections 4 and 5, we list the notation we use in this paper in Table 1.

\section{The Basic Model}

4.1. Centralized Decision Model. First, we make the optimal decision analysis of the vertically integrated agricultural products supply chain system as a benchmark for subsequent studies. The company and the farmer make decision as the main decision-making body with the same interests in the newsvendor environment. The agricultural products supply chain system's random profit function is

$$
\pi_{\mathrm{sc}}=p \min (Q(I, r), D)-v(D-Q(I, r))^{+}-C(I),
$$

where $(z)^{+}=\max \{z, 0\}$. Since the probability distribution function of $D$ is $F(\cdot)$, we can obtain the system's expected profit by combining (1) as follows:

$$
E\left(\pi_{\mathrm{sc}}\right)=(p+v)\left(Q(I, r)-\int_{0}^{Q(I, r)} F(x) d x\right)-v \mu-C(I) .
$$

Solving the second order derivative on (2) with respect to $I$

$$
\begin{aligned}
\frac{d^{2} E\left(\pi_{s c}\right)}{d I^{2}}= & (p+v)(1-F(Q(I, r))) \frac{d^{2} Q(I, r)}{d I^{2}} \\
& -(p+v) f(Q(I, r))\left(\frac{d Q(I, r)}{d I}\right)^{2}-\frac{d^{2} C(I)}{d I^{2}} .
\end{aligned}
$$

Based on assumption, we can obtain $d^{2} C(I) / d I^{2} \geq 0$, $d Q(I, r) / d I>0$, and $d^{2} Q(I, r) / d I^{2} \leq 0$, then $d^{2} E\left(\pi_{s c}\right) / d I^{2}$ $\leq 0$, which implies that $E\left(\pi_{\mathrm{sc}}\right)$ is the concave function for $I$. Thus, the optimal $I_{\mathrm{sc}}^{*}$ satisfies the first order optimal condition, that is, $d E\left(\pi_{\mathrm{sc}}\right) / d I=0$. Furthermore, the optimal $I_{\mathrm{sc}}^{*}$ is only determined by the following formula:

$$
(p+v)\left(1-F\left(Q\left(I_{\mathrm{sc}}^{*}, r\right)\right)\right) \frac{d Q\left(I_{\mathrm{sc}}^{*}, r\right)}{d I}-\frac{d C\left(I_{\mathrm{sc}}^{*}\right)}{d I}=0 .
$$

4.2. Decentralized Decision Model. In this section, we will characterize the optimal decisions by the farmer and the 
TABLE 1: List of notation.

\begin{tabular}{|c|c|}
\hline Symbol & Description \\
\hline$I$ & $\begin{array}{c}\text { The farmer's agricultural investment level (a decision } \\
\text { variable), and } I \in[0,1]\end{array}$ \\
\hline$w_{\mathrm{C}}$ & $\begin{array}{l}\text { The guaranteed purchase price decided by the } \\
\text { company (a decision variable) }\end{array}$ \\
\hline$w$ & $\begin{array}{l}\text { The random purchase price in the random demand } \\
\text { market (a random variable) }\end{array}$ \\
\hline$h(\cdot)$ & The PDF function of the random variable $w$ \\
\hline$H(\cdot)$ & The CDF function of the random variable $w$ \\
\hline$w_{\mathrm{F}}$ & The farmer's reservation price (an exogenous variable) \\
\hline$p$ & The company's selling price (an exogenous variable) \\
\hline$r$ & $\begin{array}{c}\text { The average amount of rainfall during the production } \\
\text { of agricultural products }\end{array}$ \\
\hline$\underline{\underline{r}}$ & $\begin{array}{l}\text { The lower bound of the rainfall suitable for the growth } \\
\text { of the crop }\end{array}$ \\
\hline$\underline{r}$ & $\begin{array}{l}\text { The upper bound of the rainfall suitable for the growth } \\
\text { of the crop }\end{array}$ \\
\hline$r_{1}$ & $\begin{array}{l}\text { The lower bound of disastrous rainfall experienced } \\
\text { during the growth of the crop }\end{array}$ \\
\hline$r_{2}$ & $\begin{array}{c}\text { The upper bound of disastrous rainfall experienced } \\
\text { during the growth of the crop }\end{array}$ \\
\hline $\bar{r}$ & The upper bound of rainfall that may occur in nature \\
\hline$Q(I, r)$ & The output of agricultural product \\
\hline$C(I)$ & The farmer's production cost \\
\hline$D$ & The random demand function (a random variable) \\
\hline$f(\cdot)$ & The PDF function of the random variable $D$ \\
\hline$F(\cdot)$ & The CDF function of the random variable $D$ \\
\hline$\mu$ & The expected demand \\
\hline$v$ & The unit cost of shortage \\
\hline$\pi_{\mathrm{F}}(\cdot)$ & $\begin{array}{l}\text { The expected profit of the farmer in } \\
\text { decentralized system }\end{array}$ \\
\hline$\pi_{\mathrm{C}}(\cdot)$ & $\begin{array}{l}\text { The expected profit of the company in } \\
\text { decentralized system }\end{array}$ \\
\hline$\left(1+\alpha_{1}\right) r_{1}$ & $\begin{array}{l}\text { The lower bound of rainfall index where } \\
\text { payments begin }\end{array}$ \\
\hline$\left(1+\alpha_{2}\right) r_{1}$ & The upper bound of rainfall index where payments end \\
\hline$\Delta$ & The upper bound of unit insurance compensation \\
\hline$k$ & The unit insurance premiums \\
\hline$n$ & The total amount of insurance purchased by the farmer \\
\hline$\varphi$ & The fraction of the supply chain revenue to the farmer \\
\hline$T$ & The risk transfer fee \\
\hline$\pi_{\mathrm{F}}^{W I}(\cdot)$ & $\begin{array}{l}\text { The expected profit of the farmer in decentralized } \\
\text { system under weather index insurance contract }\end{array}$ \\
\hline$\pi_{\mathrm{C}}^{W I}(\cdot)$ & $\begin{array}{l}\text { The expected profit of the company in decentralized } \\
\text { system under weather index insurance contract }\end{array}$ \\
\hline$\pi_{\mathrm{sc}}(\cdot)$ & The total expected profit in the centralized system \\
\hline
\end{tabular}

company in the decentralized supply chain system. We will study this in two steps in reverse order.

First, we consider the optimal decision of agricultural investment level of the farmer. Under the protection price designed by the company, the farmer's random profit function is

$$
\pi_{\mathrm{F}}=\max \left\{w_{\mathrm{C}}, w\right\} Q(I, r)-C(I) .
$$

Since the probability distribution function of $w$ in the interval $[L, U]$ is $H(\cdot)$, the farmer's expected profit can be achieved from (5)

$$
E\left(\pi_{\mathrm{F}}\right)=\left(U-\int_{w_{\mathrm{C}}}^{U} H(w) d w\right) Q(I, r)-C(I) .
$$

Solving the second order derivative on (6) with respect to $I$

$$
\frac{d^{2} E\left(\pi_{\mathrm{F}}\right)}{d I^{2}}=\left(U-\int_{w_{C}}^{U} H(w) d w\right) \frac{d^{2} Q(I, r)}{d I^{2}}-\frac{d^{2} C(I)}{d I^{2}} .
$$

As $d^{2} C(I) / d I^{2} \geq 0, d^{2} Q(I, r) / d I^{2} \leq 0$, and $d^{2} E\left(\pi_{\mathrm{F}}\right) / d I^{2}$ $\leq 0$,we know that $E\left(\pi_{\mathrm{F}}\right)$ is the concave function with respect to $I$. Thus, the optimal $I_{d}^{*}$ exists and satisfies the first order optimal condition $d E\left(\pi_{f}\right) / d I=0$. The optimal $I_{d}^{*}$ can only be determined by the following formula:

$$
\left(U-\int_{w_{C}}^{U} H(w) d w\right) \frac{d Q\left(I_{d}^{*}, r\right)}{d I}-\frac{d C\left(I_{d}^{*}\right)}{d I}=0 .
$$

Next, we analyze the decision on the guaranteed purchase price decided by the company. The company's random profit function is

$$
\pi_{\mathrm{C}}=p \min (Q(I, r), D)-v(D-Q(I, r))^{+}-\max \left\{w_{\mathrm{C}}, w\right\} Q(I, r) .
$$
profit

From formula (9), we can get the company's expected

$$
\begin{aligned}
E\left(\pi_{\mathrm{C}}\right)= & (p+v)\left(Q(I, r)-\int_{0}^{Q(I, r)} F(x) d x\right) \\
& -v \mu-\left(U-\int_{w_{\mathrm{C}}}^{U} H(w) d w\right) Q(I, r) .
\end{aligned}
$$

Solving the second order derivative on (10) with respect to $w_{\mathrm{C}}$

$$
\frac{d^{2} E\left(\pi_{\mathrm{C}}\right)}{d w_{\mathrm{C}}^{2}}=-h\left(w_{\mathrm{C}}\right) Q(I, r)<0 .
$$

We can know that $E\left(w_{\mathrm{C}}\right)$ is the concave function with respect to the minimum purchase price $w_{C}$. Since 
$d E\left(\pi_{\mathrm{C}}\right) / d w_{\mathrm{C}}=-H\left(w_{\mathrm{C}}\right) Q(I, r)<0$, the optimal minimum purchase price decided by the company shall not be lower than the reservation price of agricultural products sold by the farmer, namely, $w_{\mathrm{C}}^{*}=w_{\mathrm{F}}$. At the same time, when a rational company purchases agricultural products from the farmer, it needs to satisfy its marginal revenue greater than zero, otherwise, the rational company will not purchase the agricultural products produced by the farmer, that is, $d E\left(\pi_{\mathrm{C}}\right) / d Q>0$ should be met with. Combined with (10), it can be analyzed that after the growing season, the company's performance of contracts for the acquisition of agricultural products shall satisfy the following conditions:

$$
U-\int_{w_{\mathrm{C}}}^{U} H(w) d w<(p+v)(1-F(Q(I, r))) .
$$

From the above analysis, we can see that the best decision of the company when satisfying the acquisitionconstraint formula is to purchase the agricultural products with the optimal minimum price from the farmer's reservation price. Further combined with (8) analysis, $I_{d}^{*}$ under the decentralized decision can only be determined by the following formula:

$$
\left(U-\int_{w_{\mathrm{F}}}^{U} H(w) d w\right) \frac{d Q\left(I_{d}^{*}, r\right)}{d I}-\frac{d C\left(I_{d}^{*}\right)}{d I}=0 .
$$

4.3. Comparison between Centralized and Decentralized Chains. In this section, we compare the results of the centralized supply chain with those by the decentralized supply chain systems. Comparing (4) and (13), we obtain the following results.

Proposition 1. When the farmer suffers heavy rain during the agricultural production $r \in\left[r_{1}, r_{2}\right)$, both $I_{d}^{*}$ and $I_{\mathrm{sc}}^{*}$ are monotone decreasing function with respect to rainfall $r$, and $I_{d}^{*}<I_{\mathrm{sc}}^{*}$.

Proof 1. We first analyze the influence of the rainfall $r$ on optimal investment level $I_{\mathrm{sc}}^{*}$ under the centralized decision. We follow Brânzei et al. [37], solving the mixed partial derivative on (2) with respect to $(I, r)$, we can obtain

$$
\frac{\partial^{2} E\left(\pi_{\mathrm{sc}}\right)}{\partial I \partial r}=(p+v)(1-F(Q(I, r))) \frac{\partial^{2} Q(I, r)}{\partial I \partial r} .
$$

Since $(p+v)(1-F(Q(I, r))) \geq 0$ and $\partial^{2} Q(I, r) / \partial I \partial r<0$ for $r_{1} \leq r<r_{2}$, we have $\partial^{2} E\left(\pi_{\mathrm{sc}}\right) / \partial I \partial r<0$. We can see that $E\left(\pi_{\mathrm{sc}}\right)$ has submodular properties with respect to $(I, r)$. Through analysis, we can see that the optimal decision $I_{\mathrm{sc}}^{*}$ is strictly increasing regarding rainfall $r$ for $r_{1}<r \leq$ $r_{2}$. Similarly, the influence of the rainfall $r$ on optimal investment level $I_{d}^{*}$ under the decentralized decision can be analyzed to get the same conclusion: $I_{d}^{*}$ is the monotone decreasing function with respect to rainfall $r$.
Next, we need to prove $I_{d}^{*}<I_{\mathrm{sc}}^{*}$. First, we set $\tau(I)=(d$ $C(I) / d I) /(d Q(I, r) / d I)$ and solve the first order derivative of $\tau(I)$ with respect to $I$.

$$
\frac{d \tau(I)}{d I}=\frac{\left(d^{2} C(I) / d I^{2}\right)(d Q(I, r) / d I)-\left(d^{2} Q(I, r) / d I^{2}\right)(d C(I) / d I)}{(d Q(I, r) / d I)^{2}} .
$$

Since $d^{2} C(I) / d I^{2}>0, d Q(I, r) / d I>0, d^{2} Q(I, r) / d I^{2}<0$, and $d C(I) / d I>0$, we have $d \tau(I) / d I>0$. It implies that $\tau$ $(I)$ is the monotone increasing function regarding $I$. Combining with constraint condition $U-\int_{w_{C}}^{U} H(w) d w<$ $p(1-F(Q(I, r)))$, formula (4), and formula (8), we can get $I_{d}^{*}<I_{\mathrm{sc}}^{*}$. This completes the proof.

According to the analysis of Proposition 1, it can be seen that the stormy weather encountered during the agricultural production process weakens the farmer's optimal agricultural investment level, and more precipitation means lower level of agricultural investment. It implies that when severe weather occurs, the optimal decision of the farmer is made to reduce the losses caused by heavy rain by reducing the level of agricultural investment. In addition, the distorted level of agricultural investment under decentralized decision inevitably leads to a "double marginalization" and, in turn, causes a loss of performance of the entire supply chain system. It reduces the robustness of the supply chain system, which will inevitably increase the difficulty of management for the supply chain of agricultural products.

Proposition 2. When the farmer encounters stormy weather in the agricultural production process $r \in\left[r_{1}, r_{2}\right)$, the optimal profits under both centralized decision and decentralized decision satisfy $E\left(\pi_{\mathrm{F}}^{*}\left(I_{d}^{*}\right)\right)+E\left(\pi_{\mathrm{C}}^{*}\left(w_{\mathrm{C}}^{*}\right)\right)<E\left(\pi_{\mathrm{sc}}^{*}\left(I_{\mathrm{sc}}^{*}\right)\right)$.

Proof 2. For the given severe weather condition, there is the following formula

$$
\begin{aligned}
E\left(\pi_{\mathrm{F}}^{*}\left(I_{d}^{*}\right)\right)+E\left(\pi_{\mathrm{C}}^{*}\left(w_{\mathrm{C}}^{*}\right)\right)= & E\left(\pi_{\mathrm{sc}}\left(I_{d}^{*}\right)\right) \\
= & (p+v)\left(Q\left(I_{d}^{*}, r\right)-\int_{0}^{Q\left(I_{d}^{*}, r\right)} F(x) d x\right) \\
& -v \mu-C\left(I_{d}^{*}\right) .
\end{aligned}
$$

$\pi_{\mathrm{sc}}(I)$ is monotone increasing function with respect to agricultural investment level $I \in\left[0, I_{\mathrm{sc}}^{*}\right]$. Based on the analysis of Proposition 1, we can see $I_{d}^{*}<I_{\mathrm{sc}}^{*}$. It is straightforward to show that $E\left(\pi_{\mathrm{sc}}\left(I_{d}^{*}\right)\right)<E\left(\pi_{\mathrm{sc}}^{*}\left(I_{\mathrm{sc}}^{*}\right)\right)$. This completes the proof.

According to the analysis of Proposition 2, we can see that the total profit of the company and the farmer under the decentralized decision is less than the profit under the centralized decision. It shows that when the company and the farmer are maximizing their own profits, they make decisions for their own maximum benefits instead of the 
benefit of the supply chain system, which leads to a loss of performance in the supply chain system. Therefore, it is necessary to design a reasonable mechanism to improve the farmer's optimal agricultural investment level under decentralized decision so as to ease the "double marginalization" brought about by the distorted investment level of agricultural resources, so as to ensure the stable operation of the supply chain system.

\section{Risk Transfer Mechanism Based on Weather Index Insurance}

Under decentralized decision, the farmer is solely responsible for the uncontrollable weather risk encountered in the agricultural production process, and the company is solely responsible for the uncertainty demand risk, including the risk of product surplus or stock loss due to mismatch of supply and demand. In addition, severe weather exacerbates the "double marginalization." Therefore, it is necessary to design a reasonable coordination mechanism to transfer severe weather risk in order to improve the performance of the company and the farmer and achieve the perfect coordination of the agricultural products supply chain.

The heavy rain in agricultural production directly affects agricultural production, which in turn leads to a decrease in the output of agricultural products. This will be detrimental to the increase of farmer's income. The farmer can buy rain index insurance from the insurance market to hedge stormy weather risk, in order to avoid the production loss caused by heavy rain. However, based on the reality of "small farmers and large markets" in developing economies, small farmers often lack the incentive to actively purchase weather (rainfall) index insurance. The company, as a leader in the supply chain of agricultural products, in order to encourage farmers to purchase insurance to hedge against disastrous weather risk, designs a risk transfer mechanism based on rainfall index insurance on the basis of the protection price $\max \left\{w_{\mathrm{C}}, w\right\}$. Under this coordination mechanism, the company and the farmer agree that the company purchases all the agricultural products produced by the farmer at the protection price $\max \left\{w_{\mathrm{C}}, w\right\}$ at the end of the growing season. At the same time, the company distributes $\varphi$ the fraction of the actual sales revenue of the products to the farmer after the sales season so as to encourage the farmer to buy rainfall index (WI) before the growing season.

For the quantitative characterization of rainfall index insurance, we refer to a weather index insurance payment method proposed by Skees [38]. We assume that the farmer needs to pay $k$ for the purchase of unit insurance from the insurance company, and the total amount of insurance purchased is $n$. Under the insurance contract, if the average rainfall during the production process is higher than the strike, which is defined by the level of rainfall where payments begin (usually as a percentage of average) [38], the farmer can request the insurance company to compensate according to the insurance contract, in which the unit compensation upper bound is $\Delta$. The specific compensation method for rainfall index insurance is unit insurance compensation amount $=($ actual rainfall - insurance compensation point)/(rainfall index compensation upper limit-insurance compensation point) ${ }^{*}$ unit insurance compensation upper limit.

At present, in the practical operation of the rainfall index insurance, the upper bound of the insurance compensation index and the insurance compensation point are mainly determined by the percentage of the average rainfall exceeding the trigger point of the rainfall affecting the crop growth. We assume $\alpha_{1}$ and $\alpha_{2}$ are the percentages that the rainfall is higher than strike, and $\alpha_{2}>\alpha_{1}$. $\left(1+\alpha_{1}\right) r_{1}$ is the lower bound of the rainfall index where insurance payments begin; $\left(1+\alpha_{2}\right) r_{1}$ is the upper bound of the rainfall index where insurance payments end, and we assume $\left(1+\alpha_{2}\right) r_{1} \leq r_{2}$. The farmer can get the following insurance compensation if they encounter the severe weather in the production process after buying unit weather index insurance.

$$
\Theta(r)=\min \left(\Delta,\left(\frac{r-\left(1+\alpha_{1}\right) r_{1}}{\left(1+\alpha_{2}\right) r_{1}-\left(1+\alpha_{1}\right) r_{1}} \Delta\right)^{+}\right) .
$$

Without loss of generality, we assume $\alpha_{1}=0$, which means that the farmer will be paid in case of disastrous weather. In addition, the purchase of weather index insurance for farmer needs to satisfy two constraint conditions: (i) $k<\Delta$, which means that the expenditure for unit insurance expense should be less than the maximum compensation for unit insurance; and (ii) $E\left(\pi_{\mathrm{sc}}\left(I_{\mathrm{sc}}^{*}\right)\right)-E$ $\left(\pi_{\mathrm{sc}}\left(I_{d}^{*}\right)\right)>n k$, which means that the increase in expected profit from raising the level of agricultural investment should be greater than that of the purchase expense of insurance. Otherwise, the rational farmer will not purchase insurance. Based on the above analysis, the unit insurance compensation $\Theta(r)$ should be characterized as follows:

$\Theta(r)=\left\{\begin{array}{c}0, \quad 0 \leq r \leq\left(1+\alpha_{1}\right) r, \\ \frac{r-\left(1+\alpha_{1}\right) r_{1}}{\left(1+\alpha_{2}\right) r_{1}-\left(1+\alpha_{1}\right) r_{1}} \Delta, \quad\left(1+\alpha_{1}\right) r_{1}<r \leq\left(1+\alpha_{2}\right) r, \\ \Delta, \quad\left(1+\alpha_{2}\right) r_{1}<r \leq \bar{r} .\end{array}\right.$

After implementing the risk transfer mechanism $(W I, \varphi)$ based on rainfall index insurance, the company's random profit function is

$$
\begin{aligned}
\pi_{\mathrm{C}}^{W I}= & (1-\varphi) p \min (Q(I, r), D)-\max \left\{w_{\mathrm{C}}, w\right\} Q(I, r) \\
& -v(D-Q(I, r))^{+} .
\end{aligned}
$$


From (19), we can obtain the company's expected profit

$$
\begin{aligned}
E\left(\pi_{\mathrm{C}}^{W I}\right)= & ((1-\varphi) p+v)\left(Q(I, r)-\int_{0}^{Q(I, r)} F(x) d x\right) \\
& -v \mu-\left(U-\int_{w_{\mathrm{F}}}^{U} H(w) d w\right) Q(I, r) .
\end{aligned}
$$

The farmer's random profit function is

$$
\begin{aligned}
\pi_{\mathrm{F}}^{W I}= & \max \left\{w_{\mathrm{C}}, w\right\} Q(I, r)+\varphi p \min (Q(I, r), D) \\
& -C(I)-n k+n \Theta(r) .
\end{aligned}
$$

From (21), we can obtain the farmer's expected profit

$$
\begin{aligned}
E\left(\pi_{\mathrm{F}}^{W I}\right)= & \left(U-\int_{w_{\mathrm{F}}}^{U} H(w) d w\right) Q(I, r) \\
& +\varphi p\left(Q(I, r)-\int_{0}^{Q(I, r)} F(x) d x\right) \\
& -C(I)-n k+n \Theta(r) .
\end{aligned}
$$

Proposition 3. Under the risk transfer mechanism $(W I, \varphi)$, if the revenue share parameter $\varphi\left(r, w_{\mathrm{F}}\right)$ meets the following conditions,

$$
\varphi\left(r, w_{\mathrm{F}}\right)=1-\frac{\left(U-\int_{w_{\mathrm{F}}}^{U} H(w) d w\right)-v\left(1-F\left(Q\left(I_{\mathrm{sc}}^{*}, r\right)\right)\right)}{p\left(1-F\left(Q\left(I_{\mathrm{sc}}^{*}, r\right)\right)\right)},
$$

it can realize the coordination of agricultural products supply chain.

Proof 3. First, we solve the farmer's optimal agricultural investment level under the risk transfer mechanism $(W I, \varphi)$ and then solve the second order derivative on (22) with respect to $I$. We can obtain

$$
\begin{aligned}
\frac{d^{2} E\left(\pi_{\mathrm{F}}^{W I}\right)}{d I^{2}}= & \left(\left(U-\int_{w_{\mathrm{F}}}^{U} H(w) d w\right)+\varphi p(1-F(Q(I, r)))\right) \frac{d^{2} Q(I, r)}{d I^{2}} \\
& -\varphi p f(Q(I, r))\left(\frac{d Q(I, r)}{d I}\right)^{2}-\frac{d^{2} C(I)}{d I^{2}}
\end{aligned}
$$

Since $d^{2} Q(I, r) / d I^{2}<0, d Q(I, r) / d I>0$, and $d^{2} C(I) / d I^{2}$ $>0$, we can get $d^{2} E\left(\pi_{\mathrm{F}}^{W I}\right) / d I^{2}<0$. It is straightforward to show that optimal $I_{d}^{*}$ satisfies the first order optimal condition $d E\left(\pi_{\mathrm{F}}^{W I}\right) / d I=0$. So the optimal agricultural investment level $I_{d}^{*}$ exists after buying rainfall index insurance. It can only be determined by the following formula:

$$
\left(\left(\left(U-\int_{w_{\mathrm{F}}}^{U} H(w) d w\right)+\varphi p\left(1-F\left(Q\left(I_{d}^{*}, r\right)\right)\right)\right) \frac{d Q\left(I_{d}^{*}, r\right)}{d I}-\frac{d C\left(I_{d}^{*}\right)}{d I}\right)=0
$$

When the decision-making level of the optimal agricultural investment under both centralization and decentralization is the same, the coordination of the supply chain system can be achieved. Put formula (23) into formula (25) and combine formula (4) analysis to get $I_{d}^{*}=I_{\mathrm{sc}}^{*}$.This completes the proof.

According to the analysis of Proposition 3, under the risk transfer mechanism based on rainfall index, a reasonable revenue sharing coefficient can effectively reduce the risk of rainfall disasters borne by the farmer and help the farmer improve the optimal level of agricultural investment. When the revenue sharing coefficient provided by the company to encourage the farmer to purchase insurance meets certain conditions, the level of agricultural investment under the decentralized decision and the level of agricultural investment under the centralized decision are equal. It indicates that the risk transfer mechanism can effectively overcome the "double marginalization" in the supply chain, ensuring the robustness of the agricultural products supply chain system. In addition, further analysis of Proposition 3 leads to the following observations.

Observation 1. When rainfall $r \in\left[r_{1}, r_{2}\right)$, the revenue sharing coefficient $\varphi\left(r, w_{\mathrm{F}}\right)$ is strictly increasing with respect to rainfall $r$.

Proof 4. Taking the first order derivative of the revenue sharing coefficient $\varphi\left(r, w_{\mathrm{F}}\right)$ in formula (23) with respect to rainfall $r$, we can obtain

$$
\frac{\partial \varphi\left(r, w_{\mathrm{F}}\right)}{\partial r}=-\frac{\left(U-\int_{w_{\mathrm{F}}}^{U} H(w) d w\right) f\left(Q\left(I_{\mathrm{sc}}^{*}, r\right)\right)}{p\left(1-F\left(Q\left(I_{\mathrm{sc}}^{*}, r\right)\right)\right)^{2}} \frac{\partial Q\left(I_{\mathrm{sc}}^{*}, r\right)}{\partial r}
$$

From the assumption, we can see that $\partial Q\left(I_{\mathrm{sc}}^{*}, r\right) / \partial r<0$ for $r \in\left[r_{1}, r_{2}\right)$, then $\partial \varphi\left(r, w_{\mathrm{F}}\right) / \partial r>0$. In other words, the revenue sharing coefficient increases with the increase of rainfall 
during the production of agricultural products. This completes the proof.

From Observation 1, we find that the company's revenue sharing coefficient is positively correlated with rainfall. This is due to the fact that in developing economies farmers are mostly small-scale farmers with weak risktaking ability. Furthermore, the farmer's loss increases with the increase of rainfall. As a result, the farmers' optimal decision is to decrease the level of agricultural investment in order to reduce the loss of severe weather risk. Consequently, this objectively requires the company to increase the fraction of revenue sharing, in order to encourage farmers to increase the level of investment in agricultural resources and thus reduce the losses caused by heavy rain risk in the production process.

Observation 2. When rainfall $r \in\left[r_{1}, r_{2}\right)$, the revenue sharing coefficient $\varphi\left(r, w_{\mathrm{F}}\right)$ decreases with the increase of $w_{\mathrm{F}}$.

Proof 5. Taking the first order derivative on the revenue sharing coefficient $\varphi\left(r, w_{\mathrm{F}}\right)$ in formula (23) regarding farmer's reservation price $w_{\mathrm{F}}$, we can get

$$
\frac{\partial \varphi\left(r, w_{\mathrm{F}}\right)}{\partial w_{\mathrm{F}}}=-\frac{H\left(w_{\mathrm{F}}\right)}{p\left(1-F\left(Q\left(I_{\mathrm{sc}}^{*}, r\right)\right)\right)}<0 .
$$

That is to say, the revenue sharing coefficient of farmer from the company decreases with the increase in the reservation price of the farmer. This completes the proof.

From Observation 2, we can see that under the coordination status of the supply chain system, the revenue sharing coefficient is negatively correlated with the farmer's reservation price. This implies that when the farmer's reservation price is lower, the company's share of revenue sharing to the farmer is higher. For the company, if the farmer increases the reservation price, the company's optimal decision is to reduce the share of the revenue sharing given to the farmer to hedge against the increase in the purchase price.

By further analysis of Proposition 3 and Observations 1 and 2, we can find that although the implementation of the risk transfer mechanism can theoretically achieve the coordination of the agricultural products supply chain system, the company lacks the incentive to implement this risk transfer mechanism. This is because the farmer can obtain revenue sharing from the company and disaster compensation from the insurance market. As a result, there is a need for further innovation in the risk transfer mechanism. In order to avoid the company from independently taking on market demand risks and only farmer enjoying their risk income (from the company's revenue sharing and insurance company's compensation), it is necessary to further innovate the risk transfer mechanism. Based on $(W I, \varphi)$, the farmer should pay the company a risk transfer fee $T$. This risk transfer fee can prevent the farmer's opportunistic behavior and can be seen as a way for the farmer to share insurance benefits with the company. Under this risk transfer mechanism
$(W I, \varphi, T)$, the company and the farmer can truly become a community of "income and risk sharing". The following proposition examines the conditions so as to achieve supply chain coordination and a win-win situation for both the company and the farmer.

Proposition 4. Under the risk transfer mechanism (WI, $\varphi, T)$, if the transfer fee satisfies the following conditions:

$T \in\left[\varphi p \Upsilon+n(\Theta(r)-k)-\Delta E_{\mathrm{C}}, \varphi p \Upsilon+n(\Theta(r)-k)+\Delta E_{\mathrm{F}}\right]$,

where $\Psi=\left(U-\int_{w_{\mathrm{F}}}^{U} H(w) d w\right) Q(I, r), \quad \boldsymbol{\gamma}=Q(I, r)-\int_{0}^{Q(I, r)}$ $F(x) d x, \quad \Delta E_{\mathrm{C}}=E\left(\pi_{\mathrm{C}}^{W I}\left(w_{\mathrm{C}}^{*}\right)\right)-E\left(\pi_{\mathrm{C}}\left(w_{\mathrm{C}}^{*}\right)\right), \quad$ and $\quad \Delta E_{\mathrm{F}}=E$ $\left(\pi_{\mathrm{F}}^{W I}\left(I_{\mathrm{sc}}^{*}\right)\right)-E\left(\pi_{\mathrm{F}}\left(I_{d}^{*}\right)\right)$, then both the company and the farmer can achieve Pareto performance improvement, that is, a win-win situation.

Proof 6. Under the risk transfer mechanism $(W I, \varphi, T)$, the expected profit of the company is

$$
E\left(\pi_{\mathrm{C}}^{W I}\right)=((1-\varphi) p+v) \Upsilon-v \mu-\Psi+T .
$$

The expected profit of the farmer is

$$
E\left(\pi_{\mathrm{F}}^{W I}\right)=\Psi+\varphi p \Upsilon-C(I)-n k+n \Theta(r)-T,
$$

where $\Psi=\left(U-\int_{w_{\mathrm{F}}}^{U} H(w) d w\right) Q(I, r), \quad \boldsymbol{\Upsilon}=Q(I, r)-\int_{0}^{Q(I, r)} F$ $(x) d x$. In order to implement the risk transfer mechanism $(W I, \varphi, T)$, it needs to satisfy $E\left(\pi_{\mathrm{F}}^{W I}\left(I_{\mathrm{sc}}^{*}\right)\right) \geq E\left(\pi_{\mathrm{F}}\right.$ $\left.\left(I_{d}^{*}\right)\right), \quad E\left(\pi_{\mathrm{C}}^{W I}\left(w_{\mathrm{F}}\right)\right) \geq E\left(\pi_{\mathrm{C}}\left(w_{\mathrm{F}}\right)\right), \quad$ and $\quad w_{\mathrm{C}}^{*}=w_{\mathrm{F}}$, which means to achieve the Pareto improvement of the company and the farmer.

When $E\left(\pi_{\mathrm{C}}^{W I}\left(w_{\mathrm{C}}^{*}\right)\right)=E\left(\pi_{\mathrm{sc}}\left(I_{\mathrm{sc}}^{*}\right)\right)+n(\Theta(r)-k)-E\left(\pi_{\mathrm{F}}(\right.$ $\left.I_{d}^{*}\right)$ ), under the risk transfer mechanism, the company withdraws all profits increased from the coordination of the supply chain. Combining the formulas (2), (6), and (20), we can get $T=\varphi p \Upsilon+n(\Theta(r)-k)+\Delta E_{\mathrm{F}}$ and $\Delta E_{\mathrm{F}}=E\left(\pi_{\mathrm{F}}^{W I}\left(I_{\mathrm{sc}}^{*}\right)\right)-$ $E\left(\pi_{\mathrm{F}}\left(I_{d}^{*}\right)\right)$. When the cost of risk transfer exceeds $T$, the farmer's income will be lower than $\pi_{\mathrm{F}}\left(I_{d}^{*}\right)$. Therefore, the reasonable upper bound of the risk transfer fee should be $T_{\max }=\varphi p \Upsilon+n(\Theta(r)-k)+\Delta E_{\mathrm{F}}$. Similarly, it can be proved that the reasonable lower bound of the risk transfer fee is $T_{\text {min }}=\varphi p \Upsilon+n(\Theta(r)-k)-\Delta E_{\mathrm{C}}$, where $\Delta E_{\mathrm{C}}=E\left(\pi_{\mathrm{C}}^{W I}\left(w_{\mathrm{C}}^{*}\right)\right)$ $-E\left(\pi_{\mathrm{C}}\left(w_{\mathrm{C}}^{*}\right)\right)$.

To make the improvement of the company's and farmer's performance after the supply chain coordination accord with the Pareto principle, $\left[T_{\min }, T_{\max }\right]$ must be made nonempty.

$$
\begin{aligned}
T_{\max }-T_{\min }= & E\left(\pi_{\mathrm{sc}}\left(I_{\mathrm{sc}}^{*}\right)\right)-\left(\left(\pi_{\mathrm{C}}^{W I}\left(w_{\mathrm{C}}^{*}\right)\right)+E\left(\pi_{\mathrm{F}}\left(I_{d}^{*}\right)\right)\right) \\
& +n(\Theta(r)-k)
\end{aligned}
$$


because $E\left(\pi_{\mathrm{sc}}\left(I_{d}^{*}\right)\right)=\pi_{\mathrm{C}}^{W I}\left(w_{\mathrm{C}}^{*}\right)+E\left(\pi_{\mathrm{F}}\left(I_{d}^{*}\right)\right)$, and $\pi_{\mathrm{sc}}(I)$ is monotonically increasing for $\left[0, I_{\mathrm{sc}}^{*}\right]$. We can prove $T_{\max }-$ $T_{\min }>0$. This completes the proof.

From Proposition 4, we find that the design of risk transfer fee makes the company and the farmer have relatively stable returns. The determination of the upper and lower bounds of risk transfer fee makes the risk transfer mechanism prevent farmer from opportunistic behavior and protects the income of the farmer. In addition, the designed risk transfer mechanism is flexible, and the company and the farmer can allocate all the profits that the supply chain has coordinated to increase. The specific allocation amount depends on the respective bargaining power.

In the above, taking heavy rain disastrous weather $r$ $\epsilon\left[r_{1}, r_{2}\right)$ as an example, we studied how to design a risk transfer mechanism by which to achieve the perfect supply chain coordination. Under different weather conditions (nondisastrous weather $r \in[\underline{r}, \underline{r}) \cup\left[\underline{r}, r_{1}\right)$, disastrous weather $r \in\left[r_{1}, r_{2}\right)$, and extreme weather $r \in\left[r_{2}, \bar{r}\right]$ ), how does the risk transfer mechanism based on the weather (rainfall) index improve the performance of the company and the farmer? It needs further research. The following proposition will analyze the performance improvement of the company and the farmer based on the risk transfer mechanism of rainfall index insurance under different weather conditions $r \in[\underline{\underline{r}}, \bar{r}]$.

Proposition 5. Under the designed risk transfer mechan$\operatorname{ism}(W I, \varphi, T)$,

(i) when $r \in[\underline{r}, \tilde{r}), \quad E\left(\pi_{\mathrm{sc}}\left(I_{\mathrm{sc}}^{*}\right)\right) \geq E\left(\pi_{\mathrm{F}}^{W I}\left(I_{d}^{*}\right)\right)+E\left(\pi_{\mathrm{C}}^{W I}(\right.$ $\left.\left.w_{\mathrm{C}}^{*}\right)\right) \geq E\left(\pi_{\mathrm{C}}\left(\omega_{\mathrm{C}}^{*}\right)\right)+E\left(\pi_{\mathrm{F}}\left(I_{d}^{*}\right)\right)$, and $\tilde{r}=\left(\left(\alpha_{2}-\alpha_{1}\right)\right.$ $\left.k / \Delta+\left(1+\alpha_{1}\right)\right) r_{1}>r_{1}$;

(ii) when $r \in\left[\tilde{r}, r_{2}\right), \quad E\left(\pi_{\mathrm{F}}^{W I}\left(I_{d}^{*}\right)\right)+E\left(\pi_{\mathrm{C}}^{W I}\left(w_{\mathrm{C}}^{*}\right)\right) \geq E($ $\left.\pi_{\mathrm{sc}}\left(I_{\mathrm{sc}}^{*}\right)\right) \geq E\left(\pi_{\mathrm{C}}\left(\omega_{\mathrm{C}}^{*}\right)\right)+E\left(\pi_{\mathrm{F}}\left(I_{d}^{*}\right)\right) ;$

(iii) when $r \in\left[r_{2}, \bar{r}\right], E\left(\pi_{\mathrm{F}}^{W I}\left(I_{d}^{*}\right)\right)+E\left(\pi_{\mathrm{C}}^{W I}\left(w_{\mathrm{C}}^{*}\right)\right) \geq E\left(\pi_{\mathrm{C}}(\right.$ $\left.\left.\omega_{\mathrm{C}}^{*}\right)\right)+E\left(\pi_{\mathrm{F}}\left(I_{d}^{*}\right)\right)=E\left(\pi_{\mathrm{sc}}\left(I_{\mathrm{sc}}^{*}\right)\right)$, and $E\left(\pi_{\mathrm{C}}^{W I}\left(w_{\mathrm{C}}^{*}\right)\right) \geq$ $E\left(\pi_{\mathrm{C}}\left(\omega_{\mathrm{C}}^{*}\right)\right)$ and $E\left(\pi_{\mathrm{F}}^{W I}\left(I_{d}^{*}\right)\right) \geq E\left(\pi_{\mathrm{F}}\left(I_{d}^{*}\right)\right)$.

Proof 7. (i) For the farmer, when the amount of insurance compensation is lower than the amount paid for the purchase of the insurance, that is, $\left(r-\left(1+\alpha_{1}\right) r_{1} /\left(1+\alpha_{2}\right) r_{1}-\left(1+\alpha_{1}\right)\right.$ $\left.r_{1}\right) \Delta=\left(r-\left(1+\alpha_{1}\right) r_{1} /\left(\alpha_{2}-\alpha_{1}\right) r_{1}\right) \Delta \leq k$, we can get $r \leq\left(\left(\alpha_{2}\right.\right.$ $\left.\left.-\alpha_{1}\right) k / \Delta+\left(1+\alpha_{1}\right)\right) r_{1}=\tilde{r}$. As $\alpha_{1}=0$ and $\alpha_{2}>\alpha_{1}$ due to assumption, we can get $\tilde{r}>r_{1}$. Combined with the constraint condition $E\left(\pi_{\mathrm{sc}}\left(I_{\mathrm{sc}}^{*}\right)\right)-E\left(\pi_{\mathrm{sc}}\left(I_{d}^{*}\right)\right)>n k$, the following formula is established:

$$
E\left(\pi_{\mathrm{F}}^{W I}\left(I_{d}^{*}\right)\right)+E\left(\pi_{\mathrm{C}}^{W I}\left(w_{\mathrm{C}}^{*}\right)\right)+n\left(\min \left(\Delta,\left(\frac{r-\left(1+\alpha_{1}\right) r_{1}}{\left(1+\alpha_{2}\right) r_{1}-\left(1+\alpha_{1}\right) r_{1}} \Delta\right)^{+}\right)-k\right) \leq E\left(\pi_{\mathrm{sc}}\left(I_{\mathrm{sc}}^{*}\right)\right)
$$

Combined with $E\left(\pi_{\mathrm{F}}^{W I}\left(I_{d}^{*}\right)\right)+E\left(\pi_{\mathrm{C}}^{W I}\left(w_{\mathrm{C}}^{*}\right)\right) \geq E\left(\pi_{\mathrm{sc}}\left(I_{d}^{*}\right)\right)$ due to Proposition 3, it suffices for us to prove that $E\left(\pi_{\mathrm{sc}}(\right.$ $\left.\left.I_{\mathrm{sc}}^{*}\right)\right) \geq E\left(\pi_{\mathrm{F}}^{W I}\left(I_{d}^{*}\right)\right)+E\left(\pi_{\mathrm{C}}^{W I}\left(w_{\mathrm{C}}^{*}\right)\right) \geq E\left(\pi_{\mathrm{C}}\left(\omega_{\mathrm{C}}^{*}\right)\right)+E\left(\pi_{\mathrm{F}}\left(I_{d}^{*}\right)\right)$ for $r \in[\underline{\underline{r}}, \tilde{r})$. (ii) Similarly, as the proof process in (i), when the agricultural production process encounters severe weather, and the insurance compensation obtained by the farmer is higher than that paid for the insurance, then the formula is established.

$$
E\left(\pi_{\mathrm{F}}^{W I}\left(I_{d}^{*}\right)\right)+E\left(\pi_{\mathrm{C}}^{W I}\left(w_{\mathrm{C}}^{*}\right)\right)+n\left(\min \left(\Delta,\left(\frac{r-\left(1+\alpha_{1}\right) r_{1}}{\left(1+\alpha_{2}\right) r_{1}-\left(1+\alpha_{1}\right) r_{1}} \Delta\right)^{+}\right)-k\right)>E\left(\pi_{\mathrm{sc}}\left(I_{\mathrm{sc}}^{*}\right)\right)
$$

We can get $E\left(\pi_{\mathrm{F}}^{W I}\left(I_{d}^{*}\right)\right)+E\left(\pi_{\mathrm{C}}^{W I}\left(w_{\mathrm{C}}^{*}\right)\right) \geq E\left(\pi_{\mathrm{sc}}\left(I_{\mathrm{sc}}^{*}\right)\right) \geq E($ $\left.\pi_{\mathrm{C}}\left(\omega_{\mathrm{C}}^{*}\right)\right)+E\left(\pi_{\mathrm{F}}\left(I_{d}^{*}\right)\right)$ for $r \in[\underline{\underline{r}}, \tilde{r})$.

(iii) When the farmer encounters extreme weather $r$ $\epsilon\left[r_{2}, \bar{r}\right]$ during the production of agricultural products, it will cause total loss of agricultural products. Thus, we can get $E\left(\pi_{\mathrm{C}}\left(\omega_{\mathrm{C}}^{*}\right)\right)+E\left(\pi_{\mathrm{F}}\left(I_{d}^{*}\right)\right)=E\left(\pi_{\mathrm{sc}}\left(I_{\mathrm{sc}}^{*}\right)\right)$. Next, we will analyze the profits of the company and the farmer before and after implementing the risk transfer mechanism based on the weather index. Before the implementation of the risk transfer mechanism, the respective expected profits of the company and the farmer are

$$
\begin{aligned}
& E\left(\pi_{\mathrm{C}}\left(w_{\mathrm{C}}^{*}\right)\right)=-v \mu, \\
& E\left(\pi_{\mathrm{F}}\left(I_{d}^{*}\right)\right)=-C\left(I_{d}^{*}\right) .
\end{aligned}
$$


Under the risk transfer mechanism, the respective expected profits of the company and the farmer are

$$
\begin{aligned}
E\left(\pi_{\mathrm{C}}^{W I}\left(w_{\mathrm{C}}^{*}\right)\right) & =T-v \mu, \\
E\left(\pi_{\mathrm{F}}^{W I}\left(I_{d}^{*}\right)\right) & =n(\Delta-k)-T-C\left(I_{d}^{*}\right) .
\end{aligned}
$$

The risk transfer fee provided by the rational farmer should meet the constraint $0 \leq T \leq n(\Delta-k)$. Otherwise the farmer does not provide the risk transfer fee. As a result, from (34) and (36), we can get $E\left(\pi_{\mathrm{C}}^{W I}\left(w_{\mathrm{C}}^{*}\right)\right) \geq E\left(\pi_{\mathrm{C}}\left(\omega_{\mathrm{C}}^{*}\right)\right)$. For the farmer, from (35) and (37), we can get $E\left(\pi_{\mathrm{F}}^{W I}\left(I_{d}^{*}\right)\right) \geq E\left(\pi_{\mathrm{F}}\left(I_{d}^{*}\right)\right)$. In such condition, the Pareto improvement of the performance of both parties is realized, and the specific value of $T$ depends on the negotiation level of the company and the farmer. This completes the proof.

From Proposition 5, it can be found that (i) when noncatastrophic weather occurs in the farmer's production process, or when the farmer encounters severe weather, but the compensation from the insurance market cannot offset the purchase insurance payment, it will make the profits of the company and the farmer lower than that of the agricultural products supply chain, which means that the supply chain cannot be perfectly coordinated. (ii) When the farmer encounters severe weather during the production of agricultural products and the insurance compensation obtained from the insurance market is greater than the cost of purchasing insurance, the implementation of the risk index transfer mechanism based on the rainfall index can effectively achieve the performance improvement of the agricultural products supply chain system, and the profits of the company and the farmer are higher than the profits of the agricultural products supply chain system under the benchmark decision, which deviates from the conventional understanding of supply chain coordination. (iii) When the farmer encounters extreme weather during the production of agricultural products, it may cause total loss of agricultural products. At this time, although the company and the farmer cannot obtain profits through the sale of agricultural products, due to the implementation of a risk transfer mechanism based on the rainfall index, they can obtain benefits derived from the insurance market. Thus, both parties can achieve their own performance improvement.

According to the analysis of Proposition 5, whether or not the farmer encounters severe weather during the production process of agricultural products, the risk transfer mechanism based on the rainfall index can effectively improve the performance of the company and farmer, which indicates the risk transfer mechanism is effective and feasible. From the above analysis, the following observation can be derived.

Observation 3. Under the risk transfer mechanism $(W I, \varphi, T)$ based on rainfall index, changes in the weather will not affect the improvement of Pareto performance of the company and the farmer.

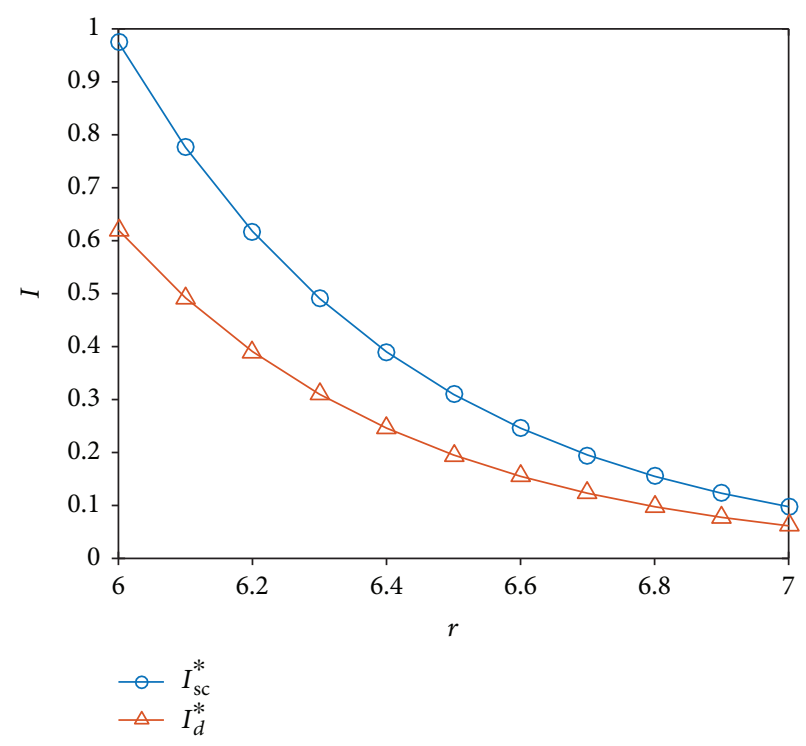

FIgURE 1: Effect of rainfall on the level of optimal agricultural investment.

\section{Numerical Illustrations}

In this section, we use case studies to study the effect of disastrous rainfall on optimal decision making and performance and to verify the effectiveness of the risk transfer mechanism based on the weather index. According to the problem description in Section 3, we assume that the output of agricultural products is $Q(I, r)=5000 I^{1 / 2} a^{-5\left(r-r_{1}\right)}$, where $a=2$, and $r_{1}=5$; the production cost of agricultural products is $C$ $(I)=200 I^{2}$; the random market purchase price $w$ and random market demand $D$ of agricultural products follow a uniform distribution in $w \sim U[0,4]$ and $D \sim U[0,10000]$, respectively. In addition, in terms of other relevant parameters, we assume $p=5, v=0.001, k=3, \Delta=12, \alpha_{2}=0.9, n=$ 50 , and $w_{\mathrm{F}}=2$.

From the analysis of Figure 1, we can see that when the agricultural production process encounters catastrophic rainfall, the optimal investment of both centralized and decentralized decision models decreases with the increase of rainfall (see Figure 1), always with a "double marginalization". This will inevitably reduce the performance of the entire supply chain, which verifies the conclusion of Proposition 1.

Figures 2 and 3 reflect the impact of the farmer's reservation prices on the performance of the farmer and the company. As can be seen from the figures, under the purchase contract signed by both parties, if the farmer increases his reservation price, it will increase individual performance (see Figure 2) but reduce the company's performance (see Figure 3). This means that for farmer, under the contract signed by both parties, the reservation price of agricultural products can be properly increased to increase their own returns. In addition, it can also be seen that changes in the minimum purchase prices of the farmer will only affect the changes in the performance of the company and the farmer 


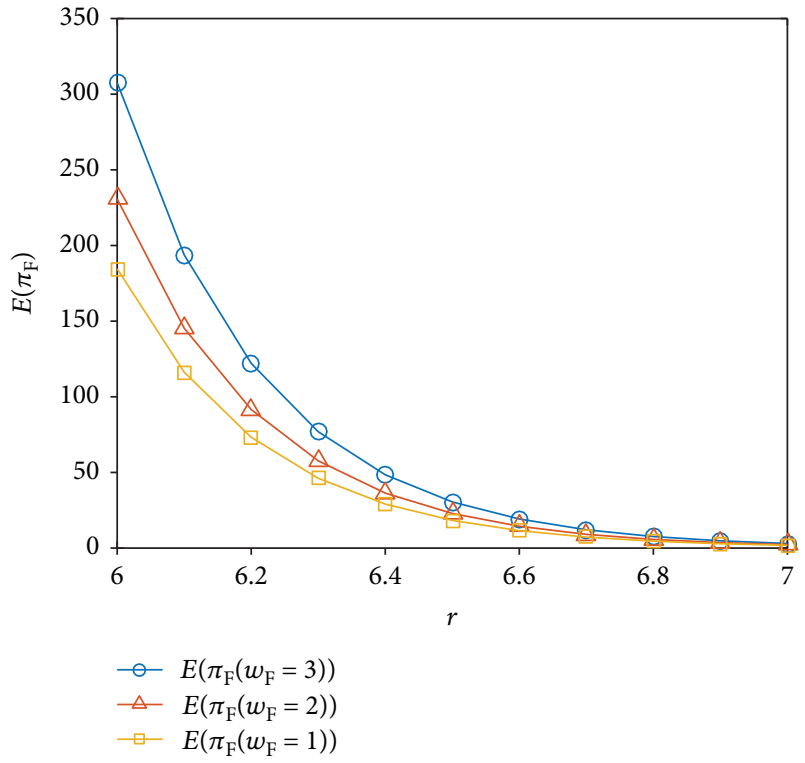

FIGURE 2: Effect of rainfall on farmer's performance under different reservation prices.

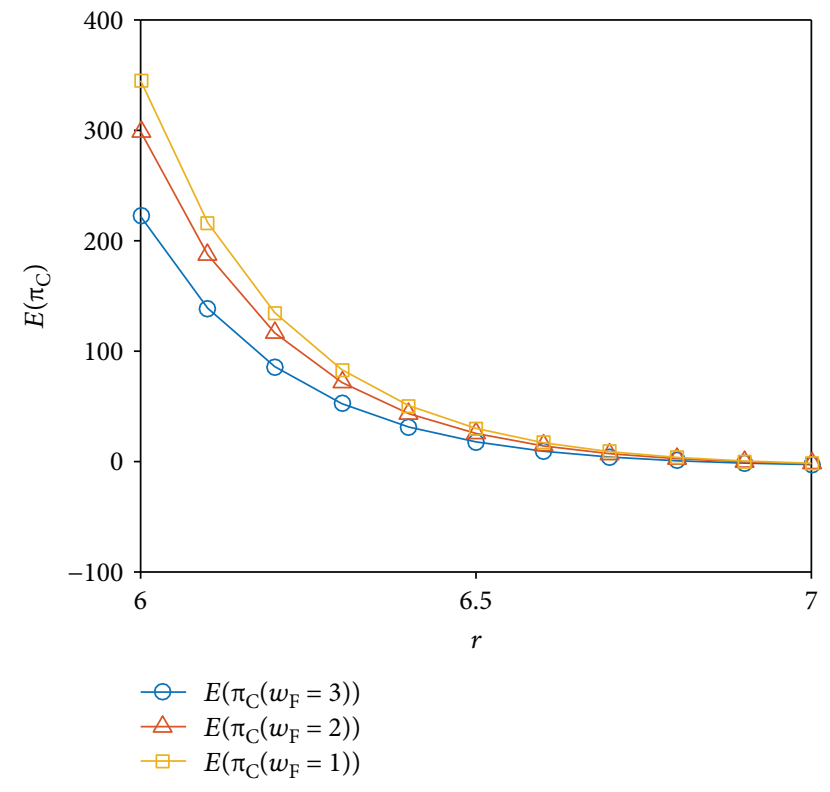

Figure 3: Effect of rainfall on the company's performance under different reservation price.

and will not change the decreasing trend of the performance of both parties as the disastrous rainfall index increases.

From the analysis of Figure 4, we can see that, with the intensification of severe weather $(r \in[5,7])$, the performance of the company and the farmer under decentralized decision and the performance of the centralized supply chain system will be reduced (see Figure 4). Combined with the analysis of Figure 1, due to the distortion of the level of agricultural investment, the decentralized supply chain system performance is lower than the centralized supply chain system performance, which verifies the conclusion in Proposition 2. In

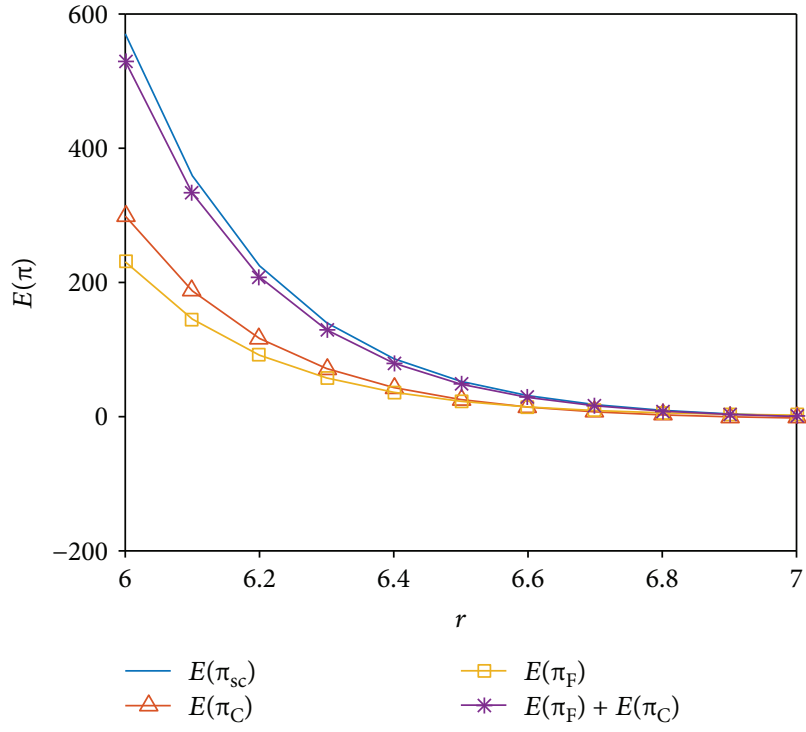

FIGURE 4: Contrast of performance of the company, farmer, and supply chain system.

addition, whether it is a centralized or decentralized decision, the performance of the company, the farmer, and supply chain systems will decrease with the increase of rainfall, which implies that with the intensification of severe rains, the risk of loss for the company and farmer will increase. Therefore, it is necessary to design a reasonable coordination mechanism to shift the weather risk faced by the company and the farmer.

Figures 5 and 6 depict the changes in profits of the company and the farmer before and after the implementation of the risk transfer mechanism. It can be seen that before the implementation of the coordination mechanism, the farmer alone undertook the weather risk in the production process, which was not conducive to improving the efficiency of agricultural production; after the implementation of the coordination mechanism, the company shares its own income to the farmer to encourage them to buy weather index insurance. The company's action can effectively improve the performance of the farmer but damage individual interests, which expands the conclusions of Proposition 3. Therefore, the risk transfer mechanism needs to be improved so that the performance of the company and the farmer can be improved.

Figure 7 shows the impact of rainfall $r$ and farmer's reservation price $w_{\mathrm{F}}$ on the revenue sharing coefficient $\varphi$ under the risk transfer mechanism. As can be seen from the figure, the revenue sharing coefficient increases with the increase of catastrophic rainfall and decreases with the increase of the reservation price of the farmer, which verifies the validity of the conclusions in Observation 1 and Observation 2. In the process of agricultural production in developing economies, farmers mostly produce in small scale, and their risk-taking capacity is weak. When the weather risk increases (i.e., $r$ increases), the income of the farmer decreases. As a result, it objectively requires the company to provide higher compensation for the farmer for risk losses. In addition, when 


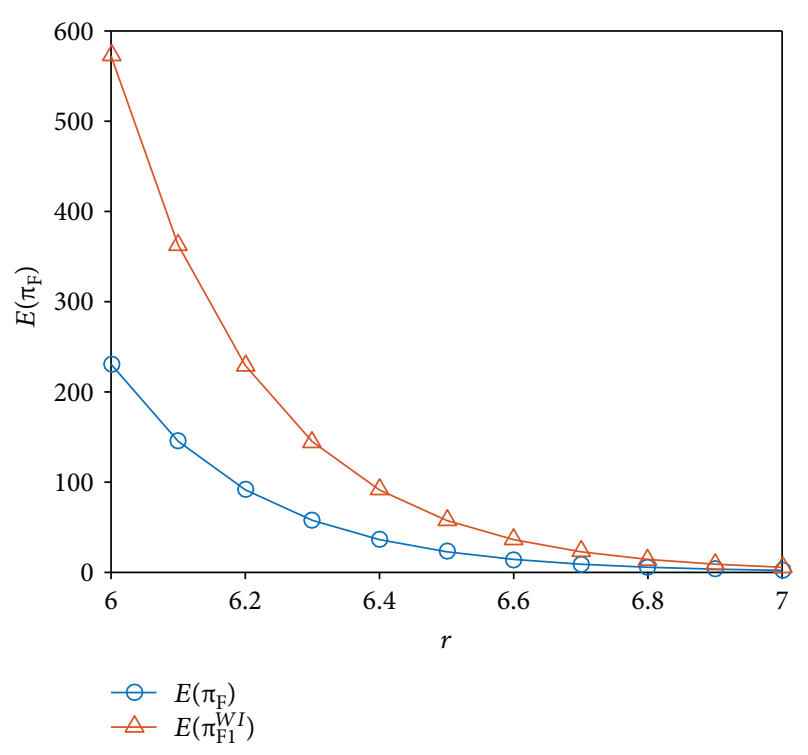

Figure 5: Change of farmer's performance before and after the implementation of $(W I, \varphi)$.

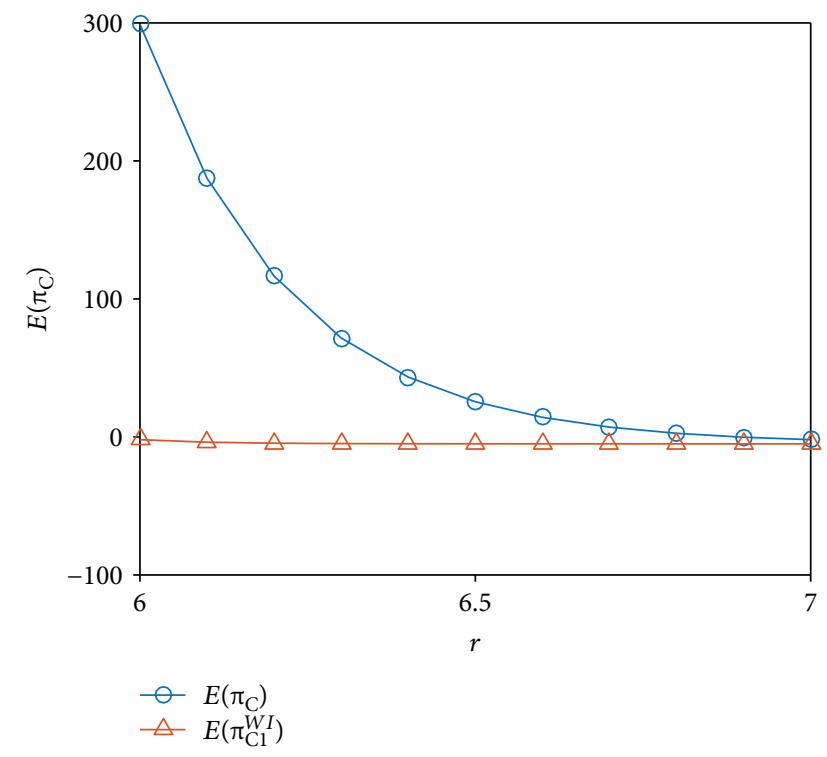

FIGURE 6: Change of the company's performance before and after the implementation of $(W I, \varphi)$.

the reservation price of the farmer increases, the revenue sharing coefficient decreases, which is due to the increase in the acquisition cost of the agricultural products. In order to ensure their own profits, the company reduces the fraction of revenue sharing in the implementation of revenue sharing.

Figures 8 and 9 demonstrate the effectiveness of the risk transfer mechanism for improving the company's and the farmer's performance. From the figures, it can be seen that the risk transfer fee based on the $(W I, \varphi)$ coordination mechanism can improve the performance of both the company and the farmer. In addition, when the amount of rainfall is large, compared with before the implementation of the contract, the profits of the company and the farmer have been

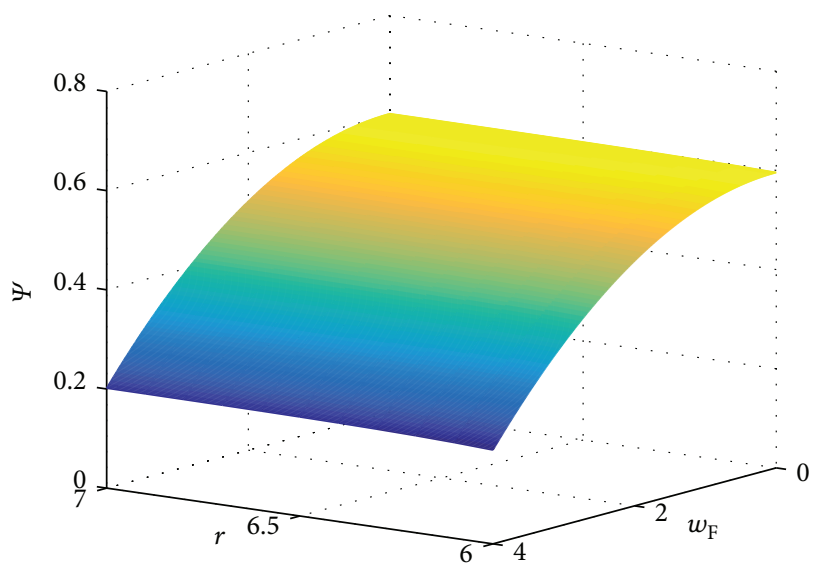

Figure 7: Effect of $w_{\mathrm{F}}$ and $r$ on $\varphi$.

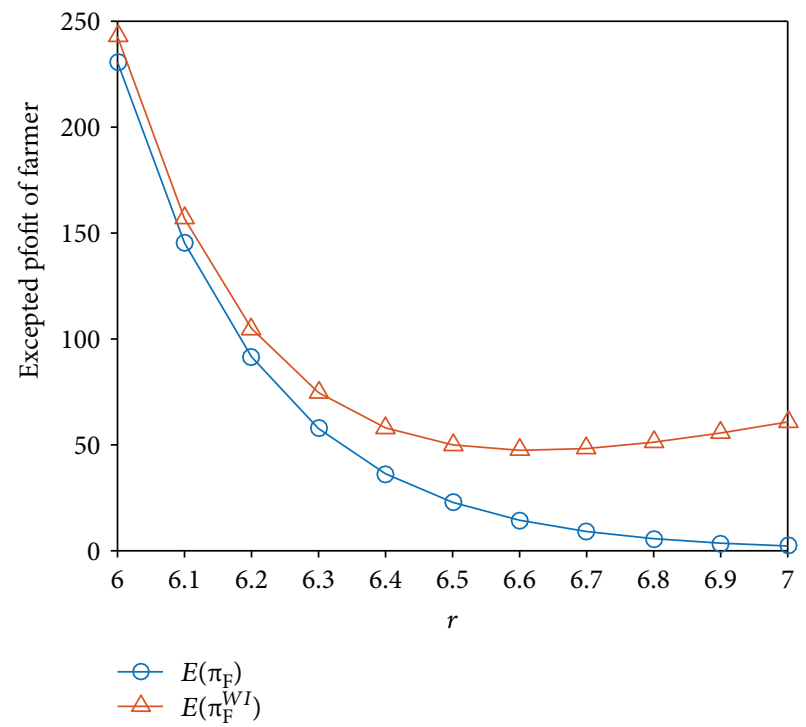

FIGURE 8: The farmer's profits before and after the implementation of $(W I, \varphi, T)$.

greatly increased, indicating that the designed coordination mechanism has a strong potential to transfer risk, and it also verifies the coordination mechanism of "rainfall index insurance + revenue sharing + risk transfer fee " is effective.

From Figure 10, we can see that after the implementation of the risk transfer mechanism $(W I, \varphi, T)$, there is a reasonable range $[300.92,325.11]$ of risk transfer fee under certain weather conditions. It can achieve a perfect coordination of the supply chain. In the range, the company and the farmer can effectively distribute the increased profits after coordination, and the specific distribution of profits depends on the respective negotiation capabilities of the parties.

From Figure 11, we can see that under the risk transfer mechanism $(W I, \varphi, T)$, when there is no disastrous weather or catastrophic weather is moderated $(r<6.125)$, the insurance compensation obtained from the insurance market is lower than the purchase insurance payment cost, which will make the decentralized supply chain performance lower than 


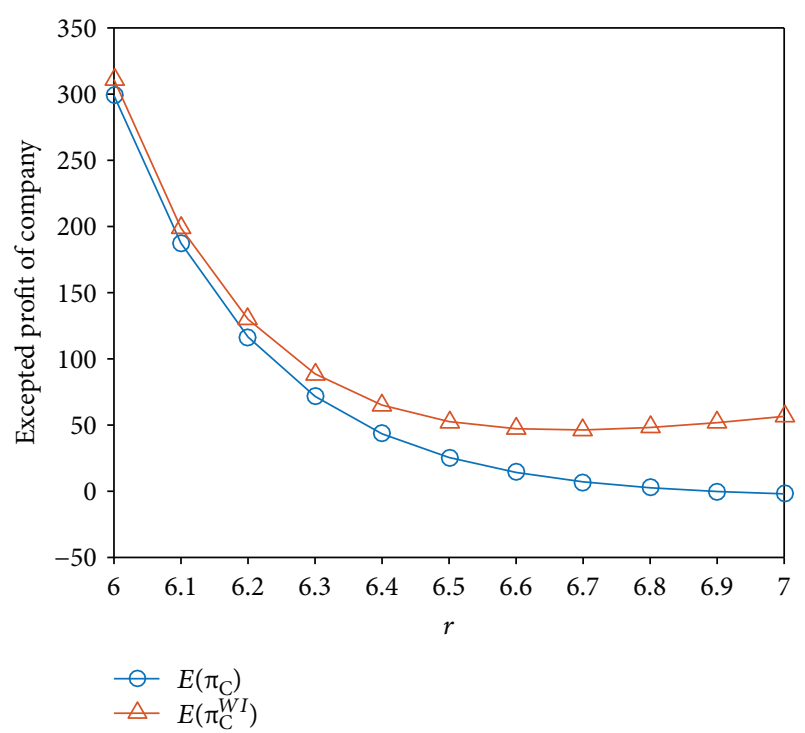

Figure 9: Profit of the company before and after the implementation of $(W I, \varphi, T)$.

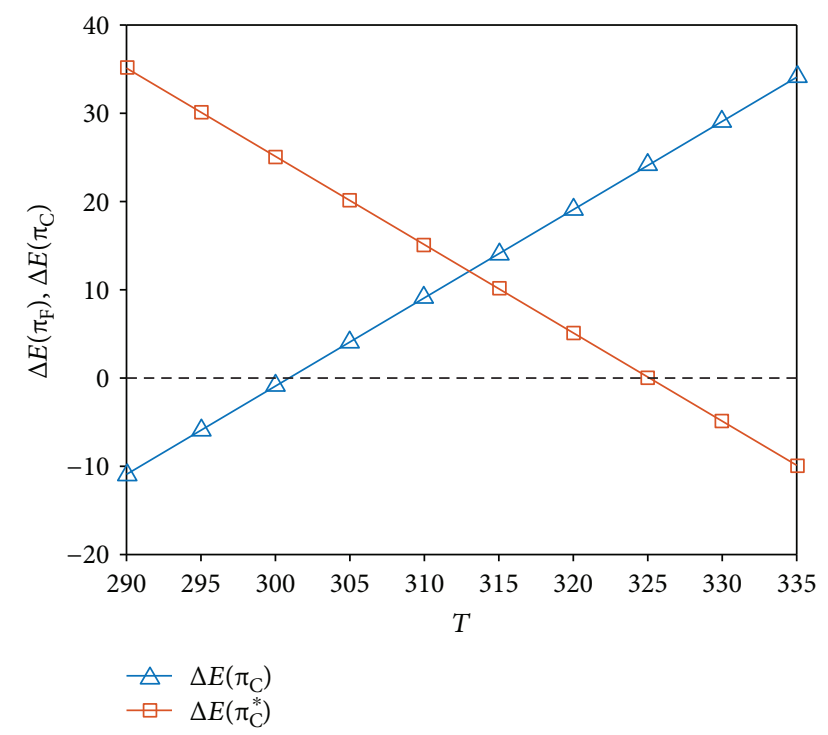

Figure 10: Effect of risk transfer fees $T$ on supply chain coordination.

centralized supply chain performance $E\left(\pi_{\mathrm{sc}}\left(I_{\mathrm{sc}}^{*}\right)\right) \geq E\left(\pi_{\mathrm{F}}^{W I}\right.$ $\left.\left(I_{d}^{*}\right)\right)+E\left(\pi_{\mathrm{C}}^{W I}\left(w_{\mathrm{C}}^{*}\right)\right)$. When disastrous weather is severe $(r \geq 6.125=\tilde{r})$, the insurance compensation obtained from the insurance market is higher than that of the purchase insurance, which makes the decentralized supply chain performance higher than the centralized supply chain performance $E\left(\pi_{\mathrm{sc}}\left(I_{\mathrm{sc}}^{*}\right)\right) \leq E\left(\pi_{\mathrm{F}}^{W I}\left(I_{d}^{*}\right)\right)+E\left(\pi_{\mathrm{C}}^{W I}\left(w_{\mathrm{C}}^{*}\right)\right)$, which effectively validates the conclusions of Proposition 5 (i) and (ii).

Figure 12 portrays the impact of risk transfer fee on the implementation of the coordination mechanism when extreme rainfall events cause total loss of agricultural products, namely, $r \in\left[r_{2}, \bar{r}\right]$. When encountering extreme weather, there is a reasonable range $(0,450)$ of risk transfer fee, which makes the performance of the company and the farmer higher than that before the implementation of the coordination mechanism. This means that when extreme weather occurs, the risk transfer mechanism $(W I, \varphi, T)$ is still valid, which effectively verifies the conclusion of Proposition 5 (iii).

A further analysis of Figures 8-12 reveals that under the rainfall index-based risk transfer mechanism $(W I, \varphi, T)$, both the company and the farmer's performance can be improved regardless of adverse weather, disastrous weather, or extreme weather. It indicates that changes in the weather will not affect the improvement of the company's and the farmer's Pareto performance, which verifies Observation 3.

\section{Conclusions}

This paper studies the coordination of two-level agricultural products supply chain system consisting of a single company and a single farmer in developing economies. Our work extends the study of supply chain coordination and agricultural products supply chain risk management, including Ye et al. [4], Zhao and Wu [5], and Chen and Yano [8]. Taking stormy weather as an example, we analyze the impact of severe weather on the optimal decision making and performance of the company and the farmer. It proposes that weather (rainfall) index insurance can be used to transfer the severe weather risk encountered in the production chain of agricultural products. A risk transfer mechanism of "rainfall index insurance + sales revenue sharing + risk transfer fee" is designed. It is used to transfer disastrous weather risk in the production process and coordinate the relations among supply chain members to encourage the company and the farmer to become the benefit community.

Through the research of this paper, we find several interesting observations and beneficial management insights in the operation of agricultural products supply chain. First, the disastrous rainfall index has a significant impact on the optimal decision making and performance of the company and the farmer. The optimal level of agricultural investment under the two decision-making models will decrease with the increase of rainfall, which indicates that the severe weather weakens the optimal decision and will cause unavoidable losses to the company and the farmer. Furthermore, disastrous rains have exacerbated the double marginalization of agricultural products supply chain. The efficiency loss of the decentralized supply chain increases with the increase of catastrophic rainfall, which will be detrimental to the cooperation between the company and the farmer. Second, the risk transfer mechanism based on the weather index can achieve the agricultural products supply chain coordination and a win-win situation. The implementation of the risk transfer mechanism can not only solve the problem of "double marginalization" in the decentralized supply chain but also enable improvement of the Pareto performance of the company and the farmer. Furthermore, we find that the company borrows the thought of risk transfer mechanism (WI, $\varphi, T)$ to design tailored mechanism for the agricultural products supply chain. The rainfall index insurance WI helps to transfer the disaster weather risk encountered during the 


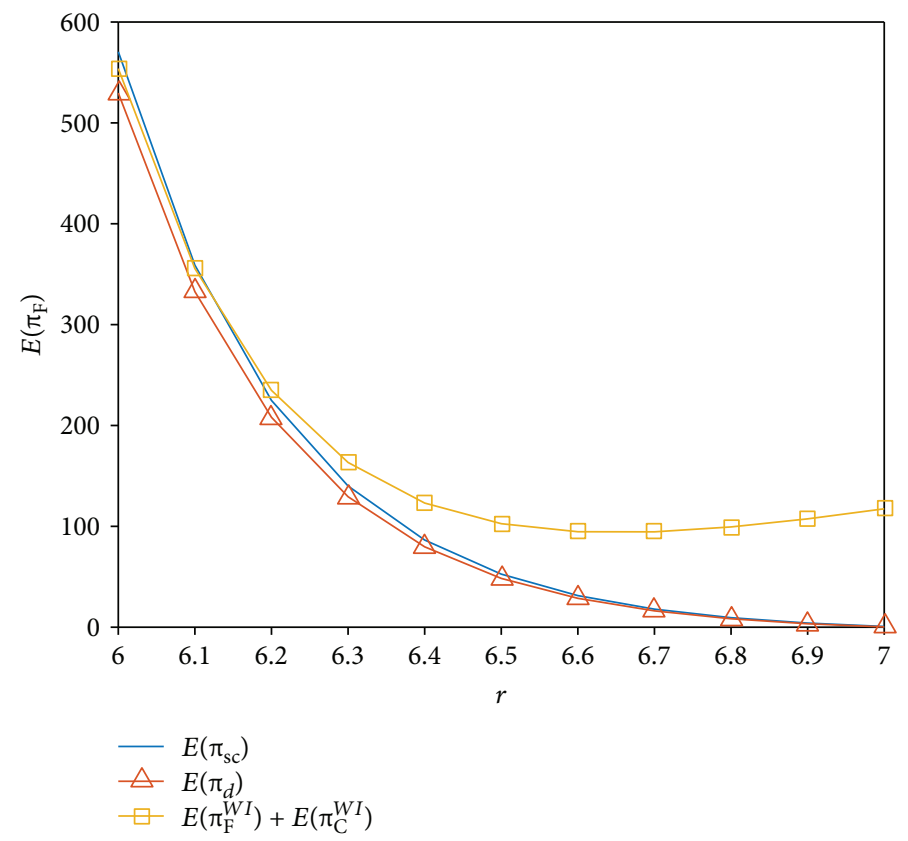

FIGURE 11: Effect of $r$ on decentralized and centralized supply chain performance before and after $(W I, \varphi, T)$.

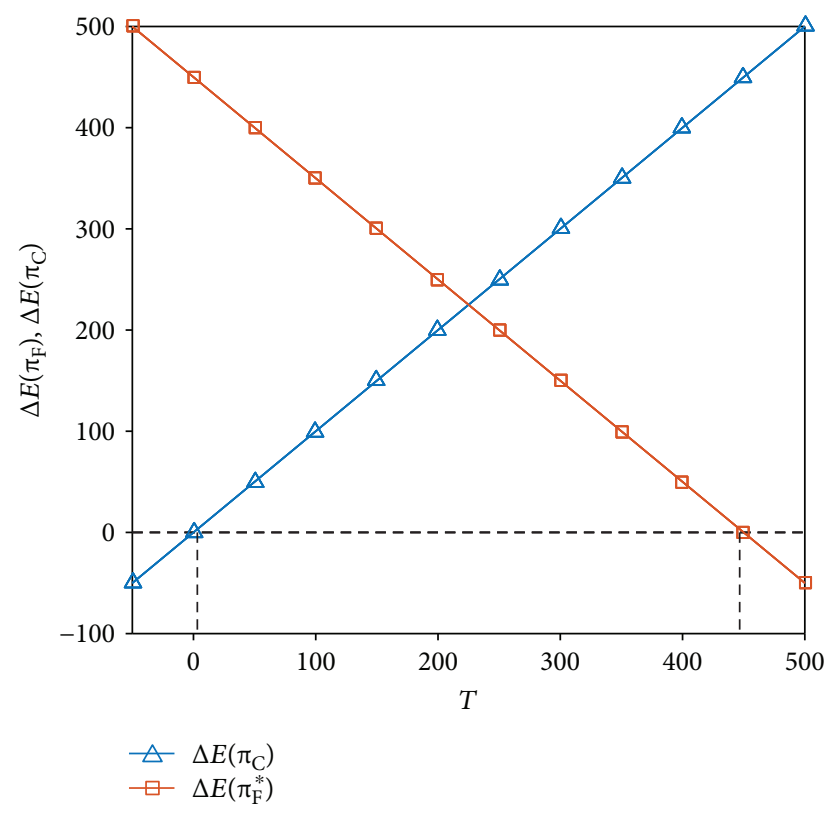

FIgURE 12: Effect of $T$ on supply chain coordination.

production process of agricultural products, the revenue sharing $\varphi$ helps in incentive and provide critical inputs to the farmer, while the risk transfer fee can help to enhance the farmer's lock-in cost and avoid the opportunist behavior. Third, in particular, when insurance compensation paid for disaster weather is higher than insurance expenditures, we obtain a conclusion that is contrary to common sense: Decentralized supply chain system performance is higher than centralized supply chain system performance. Last, under the risk transfer mechanism based on the rainfall index, although the severe weather will only reduce the performance of the company and the farmer, changes in the weather will not affect the improvement of Pareto performance of the company and the farmer. Thus, regardless of severe weather or extreme weather, the company and farmer can achieve Pareto performance improvement.

Our research still has some limitations. First, the company and farmer we studied are both risk-neutral decision makers. However, farmers in developing economies tend to have smaller production scales and are generally in a weak position in the negotiations. This determines that there may be risk preference in the production process of farmers. Therefore, research on the coordination of agricultural products supply chain with risk preference will be the next significant research point under weather-related output. Second, in order to simplify the model, we only studied the coordination problem between a single company and a single farmer. In developing economies, a company often works with multiple farmers simultaneously. Thus, the coordination of agricultural products supply chain with multiple farmers and a company will be more interesting. Third, we only studied the problem of supply chain coordination of disastrous weather-related output, but we consider that the agricultural products supply chain coordination of disastrous weather affecting both the output and the demand will be more interesting.

\section{Data Availability}

The data used to support the findings of this manuscript 2369243 are included within the supplementary materials (2369423 supplementary materials_datasets. doc). 


\section{Conflicts of Interest}

The authors declare that there are no conflicts of interest regarding the publication of this paper.

\section{Acknowledgments}

This work was supported by the National Natural Science Foundation of China (no. 71501162, 71402152, 71602014), the Youth Foundation of Humanities and Social Sciences of Ministry of Education of China (no. 14YJC630034, 15YJC630068), the Major Program of the National Social Science Foundation of China (no. 15ZDB169), the Young Teachers Academic Innovation Team Project of Southwest University of Political Science \& Law of China (no. 2016XZCXTD-10), the student research innovation program of Southwest University of Political Science \& Law (no. 2017XZXS-102), and the China Postdoctoral Science Foundation (no. 2015M580770).

\section{References}

[1] E. Regnier, "Doing something about the weather," Omega, vol. 36, no. 1, pp. 22-32, 2008.

[2] S. Dercon, "Growth and shocks: evidence from rural Ethiopia," Journal of Development Economics, vol. 74, no. 2, pp. 309-329, 2004.

[3] B. C. Liu, M. S. Li, and Z. G. Huo, "Evaluating the impacts of low-temperature, sleet and freeze disaster on the planting industry in China," Chinese Journal of Agrometeorology, vol. 29, no. 2, pp. 242-246, 2008.

[4] F. Ye, Q. Lin, and Y. Li, "Coordination for contract farming supply chain with stochastic yield and demand under CVaR criterion," Operational Research, vol. 17, no. 3, pp. 1-29, 2017.

[5] X. Zhao and F. Wu, "Coordination of agri-food chain with revenue-sharing contract under stochastic output and stochastic demand," Asia-Pacific Journal of Operational Research, vol. 28, no. 4, pp. 487-510, 2011.

[6] D. O. Ochieng, P. C. Veettil, and M. Qaim, "Farmers' preferences for supermarket contracts in Kenya," Food Policy, vol. 68, pp. 100-111, 2017.

[7] F. Ye, Y. Li, and Q. Yang, "Designing coordination contract for biofuel supply chain in China," Resources, Conservation and Recycling, vol. 128, pp. 306-314, 2018.

[8] F. Y. Chen and C. A. Yano, "Improving supply chain performance and managing risk under weather-related demand uncertainty," Management Science, vol. 56, no. 8, pp. 13801397, 2010.

[9] B. J. Barnett and O. Mahul, "Weather index insurance for agriculture and rural areas in lower-income countries," American Journal of Agricultural Economics, vol. 89, no. 5, pp. 1241-1247, 2007.

[10] G. Behzadi, M. J. O’Sullivan, T. L. Olsen, and A. Zhang, "Agribusiness supply chain risk management: a review of quantitative decision models," Omega, vol. 79, pp. 21-42, 2018.

[11] J. J. Glen, "Feature article-mathematical models in farm planning: a survey," Operations Research, vol. 35, no. 5, pp. 641-666, 1987.

[12] T. J. Lowe and P. V. Preckel, "Decision technologies for agribusiness problems: a brief review of selected literature and a call for research," Manufacturing \& Service Operations Management, vol. 6, no. 3, pp. 201-208, 2004.

[13] J. M. van Berlo, “A decision support tool for the vegetable processing industry; an integrative approach of market, industry and agriculture," Agricultural Systems, vol. 43, no. 1, pp. 91-109, 1993.

[14] B. Kazaz, "Production planning under yield and demand uncertainty with yield-dependent cost and price," Manufacturing \& Service Operations Management, vol. 6, no. 3, pp. 209-224, 2004.

[15] E. J. Lodree Jr and B. M. Uzochukwu, "Production planning for a deteriorating item with stochastic demand and consumer choice," International Journal of Production Economics, vol. 116, no. 2, pp. 219-232, 2008.

[16] O. Ahumada and J. R. Villalobos, "A tactical model for planning the production and distribution of fresh produce," Annals of Operations Research, vol. 190, no. 1, pp. 339-358, 2011.

[17] T. Paksoy, N. Y. Pehlivan, and E. Özceylan, “Application of fuzzy optimization to a supply chain network design: a case study of an edible vegetable oils manufacturer," Applied Mathematical Modelling, vol. 36, no. 6, pp. 2762-2776, 2012.

[18] X. Cai and X. Zhou, "Optimal policies for perishable products when transportation to export market is disrupted," Production and Operations Management, vol. 23, no. 5, pp. 907-923, 2014.

[19] O. Boyabatl, "Supply management in multiproduct firms with fixed proportions technology," Management Science, vol. 61, no. 12, pp. 3013-3031, 2015.

[20] S. Wiedenmann and J. Geldermann, "Supply planning for processors of agricultural raw materials," European Journal of Operational Research, vol. 242, no. 2, pp. 606-619, 2015.

[21] F. Gao, O. C. Demirag, and F. Y. Chen, "Early sales of seasonal products with weather-conditional rebates," Production and Operations Management, vol. 21, no. 4, pp. 778-794, 2012.

[22] H. Yi and Y. Li, "Risk management of agricultural supply chain in China with weather compensatory contract," E3 Journal of Business Management and Economics, vol. 4, no. 7, pp. 166172, 2013.

[23] J. L. Bertrand, X. Brusset, and M. Fortin, "Assessing and hedging the cost of unseasonal weather: case of the apparel sector," European Journal of Operational Research, vol. 244, no. 1, pp. 261-276, 2015.

[24] M. H. Hekimoğlu, B. Kazaz, and S. Webster, "Wine analytics: fine wine pricing and selection under weather and market uncertainty," Manufacturing \& Service Operations Management, vol. 19, no. 2, pp. 202-215, 2017.

[25] L. Buchheim and T. Kolaska, "Weather and the psychology of purchasing outdoor movie tickets," Management Science, vol. 63, no. 11, pp. 3718-3738, 2017.

[26] G. P. Cachon, "Supply chain coordination with contracts," Handbooks in Operations Research and Management Science, vol. 11, pp. 227-339, 2003.

[27] G. P. Cachon and M. A. Lariviere, "Supply chain coordination with revenue-sharing contracts: strengths and limitations," Management Science, vol. 51, no. 1, pp. 30-44, 2005.

[28] S. Burer, P. C. Jones, and T. J. Lowe, "Coordinating the supply chain in the agricultural seed industry," European Journal of Operational Research, vol. 185, no. 1, pp. 354-377, 2008.

[29] X. Cai, J. Chen, Y. Xiao, and X. Xu, "Optimization and coordination of fresh product supply chains with freshness-keeping 
effort," Production and Operations Management, vol. 19, no. 3, pp. 261-278, 2010.

[30] K. Chen and T. Xiao, "Reordering policy and coordination of a supply chain with a loss-averse retailer," Journal of Industrial and Management Optimization, vol. 9, no. 4, pp. 827-853, 2013.

[31] S. Asian and X. Nie, "Coordination in supply chains with uncertain demand and disruption risks: existence, analysis, and insights," IEEE Transactions on Systems, Man, and Cybernetics: Systems, vol. 44, no. 9, pp. 1139-1154, 2014.

[32] X. Y. Ren, Q. Q. Feng, S. Wang, and X. Wen, "Profit distribution of agricultural supply chain based on Shapley value," Advance Journal of Food Science and Technology, vol. 7, no. 7, pp. 479-483, 2015.

[33] L. Zhao, L. Li, Y. Song, C. Li, and Y. Wu, "Research on pricing and coordination strategy of a sustainable green supply chain with a capital-constrained retailer," Complexity, vol. 2018, Article ID 6845970, 12 pages, 2018.

[34] F. Gao, F. Y. Chen, and X. Chao, "Joint optimal ordering and weather hedging decisions: mean-CVaR model," Flexible Services and Manufacturing Journal, vol. 23, no. 1, pp. 1-25, 2011.

[35] O. Caliskan Demirag, "Performance of weather-conditional rebates under different risk preferences," Omega, vol. 41, no. 6, pp. 1053-1067, 2013.

[36] R. Amir, "Cournot oligopoly and the theory of supermodular games," Games and Economic Behavior, vol. 15, no. 2, pp. 132-148, 1996.

[37] R. Brânzei, L. Mallozzi, and S. Tijs, "Supermodular games and potential games," Journal of Mathematical Economics, vol. 39, no. 1-2, pp. 39-49, 2003.

[38] J. R. Skees, "A role for capital markets in natural disasters: a piece of the food security puzzle," Food Policy, vol. 25, no. 3, pp. 365-378, 2000. 


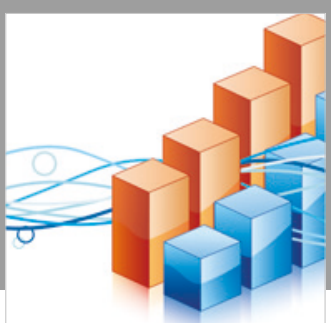

Advances in

Operations Research

\section{-n-m}
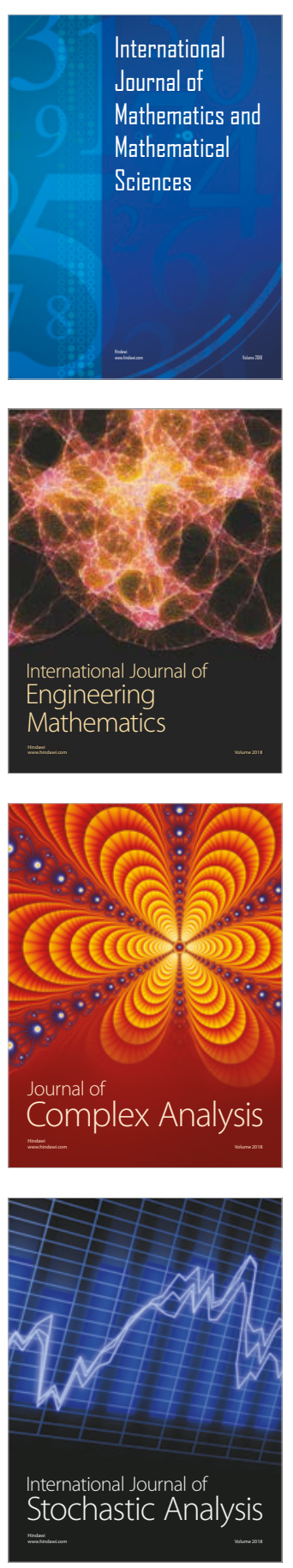
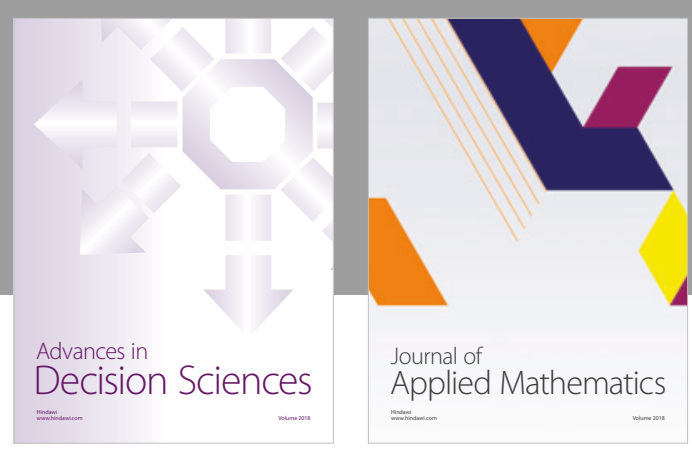

Journal of

Applied Mathematics
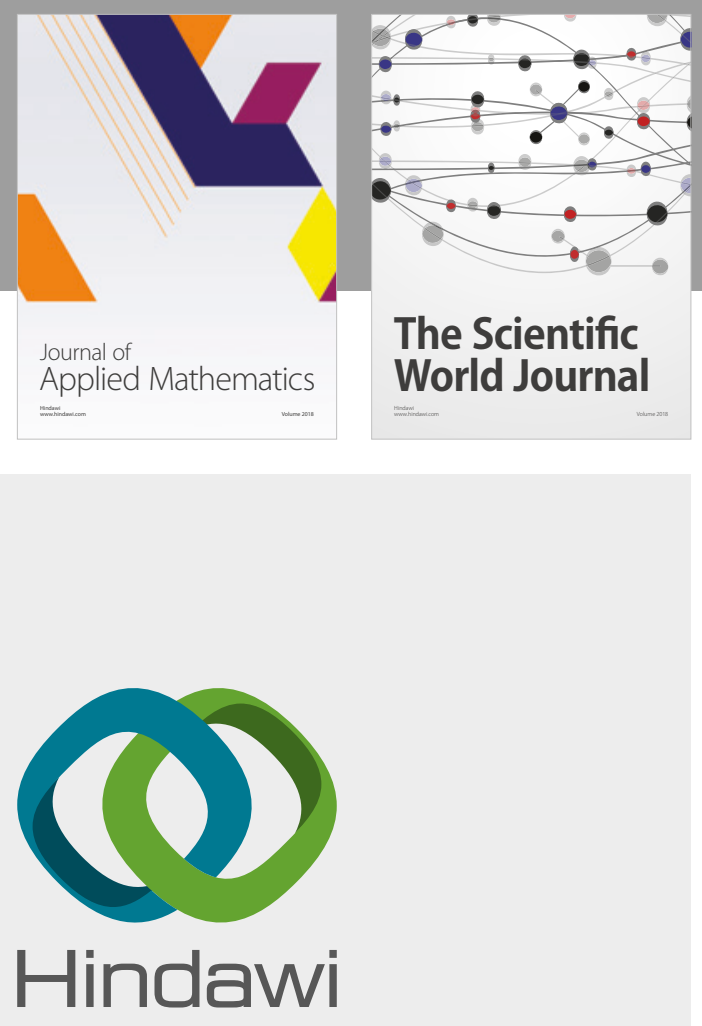

Submit your manuscripts at

www.hindawi.com

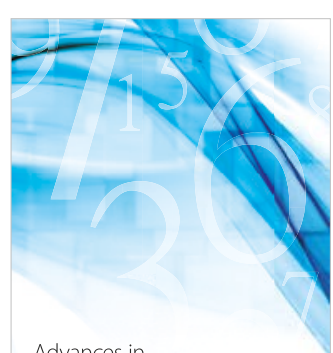

Advances in
Numerical Analysis
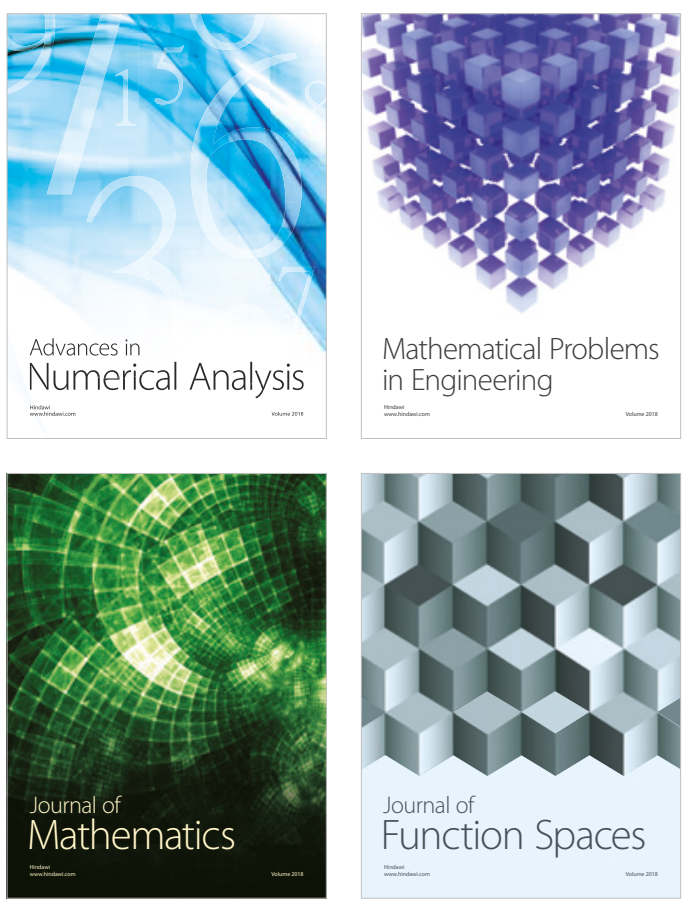

Mathematical Problems in Engineering

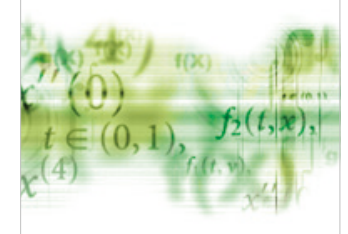

International Journal of

Differential Equations

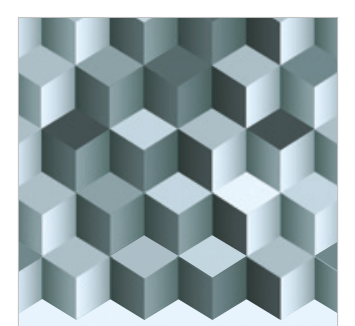

Journal of

Function Spaces
The Scientific

World Journal

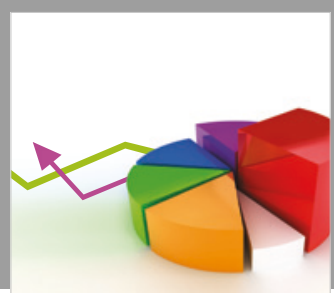

Journal of

Probability and Statistics
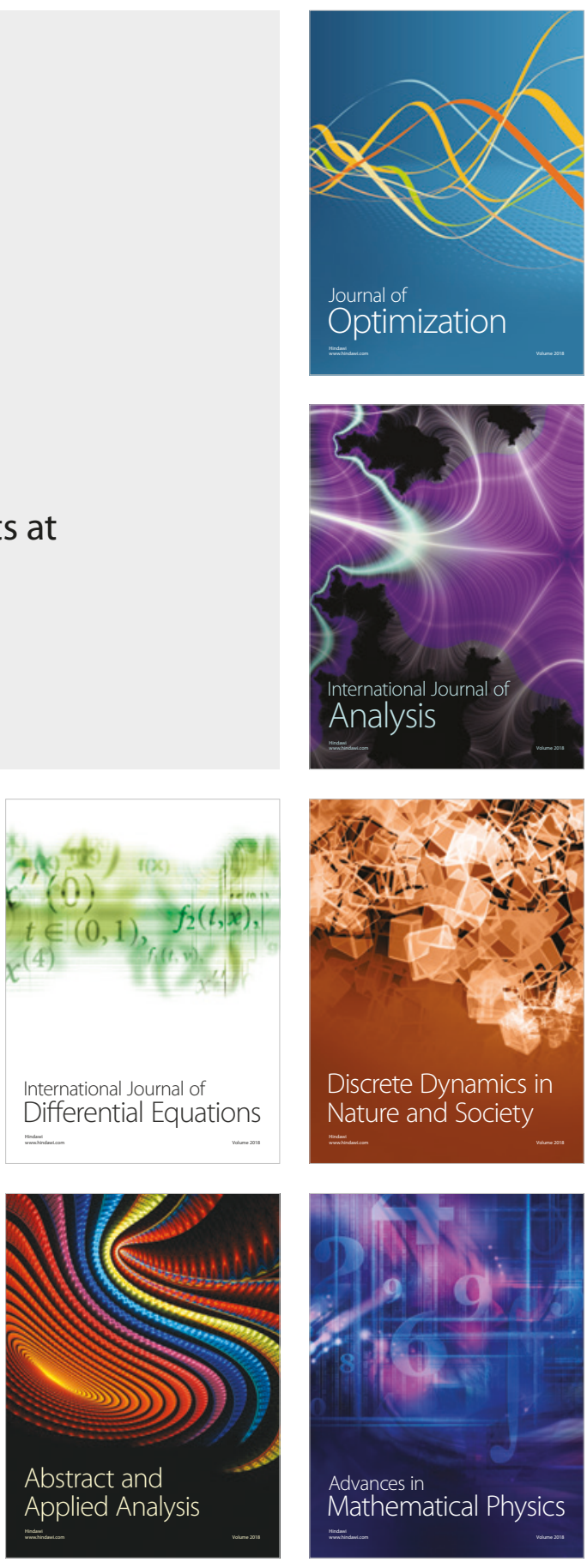